\title{
Precipitation Pathways for Ferrihydrite Formation in Acidic Solutions
}

Mengqiang Zhu, ${ }^{\dagger, \star * *}$ Cathrine Frandsen, ${ }^{\perp}$ Adam F. Wallace, ${ }^{\S}$ Benjamin Legg,, Syed Khalid, ${ }^{\Delta}$ Hengzhong Zhang, $\|$ Steen Mørup, ${ }^{\perp}$ Jillian F. Banfield $\|, *$ and Glenn A. Waychunas *

† Department of Ecosystem Science and Management, University of Wyoming, Laramie, WY, 82071

${ }^{*}$ Earth Sciences Division, Lawrence Berkeley National Laboratory, Berkeley, CA, 94720

${ }^{\perp}$ Department of Physics, Technical University of Denmark, DK-2800 Kgs. Lyngby, Denmark

$\S$ Department of Geological Sciences, University of Delaware, Newark, DE 19713

॥ Department of Earth and Planetary Science, University of California, Berkeley, CA, 94720

${ }^{\Delta}$ National Synchrotron Light Sources, Brookhaven National Laboratory, Upton, NY, 11973

Submitted to Geochimica et Cosmochimica Acta

* Corresponding author: mzhu6@uwyo.edu. Phone: + 1307 766-5523. Fax: +1 307 766-6403

(C) 2015. This manuscript version is made available under the Elsevier user license http://www.elsevier.com/open-access/userlicense/1.0/ 


\begin{abstract}
Iron oxides and oxyhydroxides form via $\mathrm{Fe}^{3+}$ hydrolysis and polymerization in many aqueous environments, but the pathway from $\mathrm{Fe}^{3+}$ monomers to oligomers and then to solid phase nuclei is unknown. In this work, using combined X-ray, UV-vis, and Mössbauer spectroscopic approaches, we were able to identify and quantify the long-time sought ferric speciation over time during ferric oxyhydroxide formation in partially-neutralized ferric nitrate solutions $\left(\left[\mathrm{Fe}^{3+}\right]=0.2\right.$ $\mathrm{M}, 1.8<\mathrm{pH}<3)$. Results demonstrate that Fe exists mainly as $\mathrm{Fe}\left(\mathrm{H}_{2} \mathrm{O}\right)_{6}{ }^{3+}, \mu$-oxo aquo dimers and ferrihydrite, and that with time, the $\mu$-oxo dimer decreases while the other two species increase in their concentrations. No larger Fe oligomers were detected. Given that the structure of the $\mu$-oxo dimer is incompatible with those of all Fe oxides and oxyhydroxides, our results suggest that reconfiguration of the $\mu$-oxo dimer structure occurs prior to further condensation leading up to the nucleation of ferrihydrite. The structural reconfiguration is likely the rate-limiting step involved in the nucleation process.
\end{abstract}

\title{
Introduction
}

Ferric iron $\left(\mathrm{Fe}^{3+}\right)$ oxides and oxyhydroxides (abbreviated as Fe oxides unless otherwise stated) are among the most important environmental minerals, playing crucial roles in nutrient cycling and contaminant fate and transport. $\mathrm{Fe}^{3+}$ hydrolysis and subsequent polymerization and precipitation is the major formation pathway of $\mathrm{Fe}$ oxides in many aqueous environments, regardless of dissolved $\mathrm{Fe}^{3+}$ existing in natural acidic waters or resulting from $\mathrm{Fe}^{2+}$ oxidation by $\mathrm{O}_{2}$ at circumneutral pH (Bligh and Waite, 2010; Bottero et al., 1994; Bottero et al., 1991; Deng, 1997; Flynn, 1984; Masion et al., 2001; Masion et al., 1997a; Masion et al., 1997b; Pokrovski et al., 2003; Rose and Waite, 2003; Rose and Waite, 2007; Rose et al., 1997a; Rose et al., 1996; Rose et al., 1997b; van Genuchten et al., 2012; van Genuchten et al., 2014a; van Genuchten et al., 2014b; Voegelin et al., 2010; Voegelin et al., 2013; Zhu et al., 2012). Knowledge of the pathway at the molecular scale has important implications for understanding the environmental mineralogy and chemistry of Fe oxides. The formation pathway likely dictates the phase diversity of Fe oxides precipitated in aqueous environments. Presumably, Fe oxide formation occurs via successive polymerization processes (Jolivet et al., 2004). Hydrolyzed Fe monomers first couple to form oligomers, such as dimers, trimers and tetramers; these oligomers then grow or aggregate chemically to form nuclei that further grow and organize into particles of well-defined structure (Johnston and Lewis, 1986; Michot et al., 2000). Molecular-scale characterization provides information, such as on what aqueous species (monomers, oligomers, particles, etc) are present 
during formation, how each polymerization step proceeds, and why certain anions (e.g., nitrate, chloride and sulfate) and physiochemical conditions direct formation of different types of nuclei and affect crystal growth. The products may be different Fe oxide phases or, the same phase but with varying chemical, structural and morphological characteristics (Jolivet et al., 2000).

Identification of the intermediate metal polymeric species is a critical step in elucidating formation mechanisms (Michot et al., 2000), and hydrolysis products, particularly oligomers and polymers, and their role in the formation of nuclei and particles, have been extensively investigated. Much information has been gained on $\mathrm{Cr}^{3+}, \mathrm{Rh}^{3+}$ and $\mathrm{Al}^{3+}$ hydrolysis and precipitation processes as these occur slowly due to slow ligand-exchange rates, allowing separation and detailed structural characterization of each intermediate formation product (Casey et al., 2009; Spiccia, 2004). However, $\mathrm{Fe}^{3+}$ hydrolysis and precipitation occurs very rapidly, and any intermediate products larger than dimers have never been isolated and successfully characterized (Casey et al., 2009), greatly hindering identification of the reaction mechanisms.

Previous studies have characterized the $\mathrm{Fe}$ species in partially neutralized $\mathrm{Fe}^{3+}$ solutions $\left(\left[\mathrm{OH}^{-}\right] /\left[\mathrm{Fe}^{3+}\right]<3\right)$ because formation driven by full neutralization occurs too rapidly to study (Bligh and Waite, 2010; Bottero et al., 1994; Bottero et al., 1991; Deng, 1997; Flynn, 1984; Masion et al., 2001; Masion et al., 1997a; Masion et al., 1997b; Pokrovski et al., 2003; Rose and Waite, 2003; Rose and Waite, 2007; Rose et al., 1997a; Rose et al., 1996; Rose et al., 1997b; Zhu et al., 2012). When $\left[\mathrm{OH}^{-}\right] /\left[\mathrm{Fe}^{3+}\right] \leq 0.5$, hydrated $\mathrm{Fe}^{3+}$ monomers and dimers are the dominant species (Zhu et al., 2013) whereas larger cationic polymers form at larger ratios $\left(\left[\mathrm{OH}^{-}\right] /\left[\mathrm{Fe}^{3+}\right]>0.5\right)$ (Flynn, 1984). Brady et al. (1968) and Magini (1977) have determined the structure of these polymers using Xray atomic pair distribution function analysis, but the Fe octahedral linkages were uncertain due to interference from the O-O pair correlations (Flynn, 1984). Bottero, Manceau, their co-workers (Combes et al., 1989; Masion et al., 2001; Masion et al., 1997a; Masion et al., 1997b; Pokrovski et al., 2003; Rose et al., 1997a; Rose et al., 1996; Rose et al., 1997b) and Pokroski et al. (Pokrovski et al., 2003) tried to resolve the polymer structure using extended X-ray absorption fine structure (EXAFS) spectroscopy. In their studies, the local atomic structures of the Fe polymers were determined using an EXAFS shell-by-shell fitting analysis. The obtained structures, consisting of $\mathrm{FeO}_{6}$ octahedra with both edge-sharing and several types of corner-sharing motifs, imply structural elements not shared by most Fe oxide phases, with the exception being those polymers that form in $\mathrm{FeCl}_{3}$ solutions and resemble akaganéite (Combes et al., 1989). In contrast, Johnston and Lewis (1986) characterized the polymers isolated by membrane-filtration from partially-neutralized $\mathrm{Fe}(\mathrm{III})$ nitrate solutions, which were aged for 48 - 143 h prior to Mössbauer spectroscopic analysis, and concluded that the polymers were similar in structure to goethite. Their study also found that upon 
aging, the dimer concentration increased whereas the monomer concentration decreased, and that oligomers (trimers, tetramers, etc.) larger than dimers were not detectable (Johnston and Lewis, 1986). Consequently, there are large discrepancies among the previous studies regarding the identities of early-formed Fe polymers, and little is known about the smaller Fe species.

In this work, we attempt to identify and quantify the Fe species present in the earliest stages of $\mathrm{Fe}$ oxyhydroxide formation in partially-neutralized acidic $\mathrm{Fe}^{3+}$ nitrate solutions using in situ time-resolved synchrotron-based X-ray diffraction (SXRD), quick-scanning EXAFS (QEXAFS), rapid UV-vis, and quenched frozen-solution Mössbauer spectroscopic analyses. The results indicate that the extended Fe polymers consist entirely of nanoparticulate ferrihydrite, and provide quantitative information about the temporal evolution of the concentration of ferrihydrite and smaller Fe species (monomers and dimers), as well as new insight into the ferrihydrite nucleation mechanism. This work also has implications for understanding $\mathrm{Fe}^{3+}$ hydrolysis and precipitation in natural acidic environments, such as acidic soils and acid mine drainage systems that have similar $\mathrm{pH}$ and $\mathrm{Fe}^{3+}$ concentration to those used in this study. In natural acidic environments, sulfate is the major dissolved anion and controls $\mathrm{Fe}^{3+}$ hydrolysis and precipitation (e.g., forming schwertmannite) because of the strong sulfate complexation to $\mathrm{Fe}^{3+}$ (Wang et al., 2015a; Zhu et al., 2014). To understand the impacts of sulfate, one must first gain sufficient understanding on $\mathrm{Fe}^{3+}$ hydrolysis and precipitation in the absence of strong $\mathrm{Fe}^{3+}$-binding ligands. Nitrate only negligibly binds $\mathrm{Fe}^{3+}$ and thus, $\mathrm{Fe}^{3+}$ hydrolysis and precipitation in nitrate solutions under the acidic conditions in this work serves well as the control system for understanding Fe(III) behavior in more complicated natural acidic environments.

\section{Experimental section}

Sample preparation: The sample preparation procedure has been described in Zhu et al. (2012). Briefly, reactions were initiated by pumping $4 \mathrm{~mL} 0.28,0.32,0.4,0.8$ or $1 \mathrm{M} \mathrm{NaHCO}_{3}$ solution at $5 \mathrm{~mL} \cdot \mathrm{min}^{-1}$ using a syringe pump into a $30 \mathrm{~mL}$ plastic bottle containing $4 \mathrm{~mL} 0.4 \mathrm{M}$ $\mathrm{Fe}^{3+}$ nitrate solution to achieve $\left[\mathrm{HCO}_{3}^{-}\right] /\left[\mathrm{Fe}^{3+}\right]$ ratio (represented by $h$ ) of $0.7,0.8,1,2$ and 2.5 . The $\mathrm{Fe}^{3+}$ concentration in the mixed solutions was $0.2 \mathrm{M}$. The weak base $\mathrm{NaHCO}_{3}$ was required to minimize the formation of immediate precipitates (Flynn, 1984) during base addition and the nitrate salt was chosen to minimize the anion effects on the particle formation when using sulfate and chloride (Combes et al., 1989; $\mathrm{Hu}$ et al., 2012; Zhu et al., 2012). Upon introduction of $\mathrm{NaHCO}_{3}$ solutions, $\mathrm{CO}_{2}$ bubbles were produced and rapidly emitting from the solutions because of the low $\mathrm{pH}(<3)$ of the mixed solutions. At such $\mathrm{pH}, \mathrm{HCO}_{3}{ }^{-}$and $\mathrm{CO}_{3}{ }^{2-}$ concentrations were minimal and not able to interfere with $\mathrm{Fe}^{3+}$ chemistry. In addition, the mixed solutions were transparent and the 
particles formed were not observed to settle over may weeks. Thus, it is extremely challenging to isolate the particles for phase identification to examine their changes with time at the early stage of particle formation. The following in situ techniques, i.e., directly measuring the partiallyneutralized solutions, are more suitable.

Reference Fe oxyhydroxide preparation: Two-line ferrihydrite was synthesized by adding $\mathrm{NaOH}$ to $\mathrm{Fe}\left(\mathrm{NO}_{3}\right)_{3}$ solution and maintaining the suspension at $\mathrm{pH} 7$, as described in $\mathrm{Zhu}$ et al. (2014). Ferrihydrite was air dried prior to XAFS data collection. The goethite $(\sim 25 \mathrm{~nm}$ nanoparticles) reported in Zhang et al. (2011) was used for XAFS data collection in this study. Lepidocrocite XAFS spectra used in this study were previously reported in Shimizu et al. (2013).

$U V$-vis Spectroscopy and $p H$ measurement. Each mixed solution was immediately transferred to a quartz cuvette (1-mm path length) and measured with an Agilent UV-Vis spectrophotometer (model 8453) for time-resolved UV-vis spectra. Five second of integration time was used for continuous recording of the spectra. Meanwhile, the solution was measured for $\mathrm{pH}$ which was automatically recorded every $20 \mathrm{~s}$ using a $\mathrm{pH}$ meter calibrated with $\mathrm{pH}$ 1, 1.68, 2 and 4 buffer solutions.

In situ time-resolved synchrotron X-ray diffraction (SXRD). Time-resolved SXRD 2-D images were collected using X-rays of $58.29 \mathrm{keV}(\lambda=0.2128 \AA)$ and a Perkin Elmer amorphous silicon detector at beamline 11-ID-B at the Advanced Photon Source, Argonne National Laboratory. The high flux of the X-rays of this beamline is the key for collecting high signal-to-noise ratio XRD data from particles in dilute particle suspensions. The mixed solutions were encapsulated in $4 \mathrm{~mm}$ diameter Kapton capillary tubes for time-resolved measurements. The first pattern for each sample was recorded at about 4 min after the initiation of the base addition, which was also true for the following QEXAFS data collection. The exposure time was $3 \mathrm{~s}$ and this was repeated 10 times for a total collection time of $30 \mathrm{~s}$ for each pattern. The XRD pattern of an un-neutralized $0.2 \mathrm{M} \mathrm{Fe}$ nitrate solution $(h=0)$ was used for background removal. The Fit2D analysis program (Hammersley, 1998) was used to integrate and convert the 2-D images to 1-D intensity versus wave vector $(\mathrm{Q})$ data. The sample-to-detector distance, beam center position and tilt angle of the detector relative to the beam path were calibrated using a $\mathrm{CeO}_{2}$ standard.

QEXAFS spectroscopy. Each mixed solution was immediately transferred to a $2 \mathrm{~mm}$ thick, $15 \mathrm{~mm}$ long and $10 \mathrm{~mm}$ wide cell made from acrylic plastic plate. Kapton film was used to seal both sides of the cell to hold the solution. QEXAFS spectra were recorded in transmission mode at one scan per $2 \mathrm{~s}$. A time-resolution of $30 \mathrm{~s}$ was resulted by averaging 14 or 15 continuous scans of 
QEXAFS spectra to improve counting statistics. The measurements were conducted using a specially equipped monochromator with a $\mathrm{Si}$ (111) crystal at beamline X18A at the National Synchrotron Light Source (Khalid et al., 2010). Higher order harmonic X-rays were minimized by detuning the monochromator by $35 \%$ with respect to $\mathrm{I}_{0}$.

The powder Fe oxyhydroxide references were ground finely and uniformly spread on Scotch tape for EXAFS data collection in transmission mode using a $\mathrm{Si}$ (220) monochromator crystal at beamline 4-1 at the Stanford Synchrotron Radiation Lightsource (SSRL).

EXAFS spectra were converted into $\mathrm{k}^{3} \chi(\mathrm{k})$ and Fourier transforms $|\chi(\mathrm{R})|$ were calculated over $\mathrm{k}=3-14 \AA^{-1}$ using the Bessel-Kaiser window function after background removal and normalization. Linear combination fitting (LCF) analysis of QEXAFS spectra was performed over $2-12.5 \AA^{-1}$ in $\mathrm{k}$ space with the component sum forced to 1.0. Only four components were used for the LCF fit of each spectrum. Athena (Ravel and Newville, 2005) was used for the above data reduction and processing. For selected samples, EXAFS shell-by-shell fitting was performed using the SixPack program (Webb, 2005) to obtain the average local atomic environment of iron atoms.

Mössbauer spectroscopy. To assist in identifying Fe species, Mössbauer spectroscopic analysis on frozen solutions was performed for the $h=1$ time series as well as the $h=0$ solution, with the latter not being observed to change with time. The $h=1$ solution was sampled at 2 min, $30 \mathrm{~min}$ and $350 \mathrm{~min}$ after the completion of base addition. Then each solution was quickly mixed with $50 \%$ glycerol (v/v), hand shaken, transferred to a plastic cylindrical container, sealed, and then immediately immersed into liquid nitrogen. This process was timed and took $90 \pm 10$ seconds per sample. During freezing, the samples were quickly and constantly moved around in the liquid nitrogen bath using a metal tweezer to hold the samples. We estimate that the freezing of each sample was completed in about 1 minute/less than 2 minutes. The frozen samples were glassy and transparent (yellow or colorless) due to the glycerol addition. We sometimes heard the formation of one large crack in the glass 1-2 minutes after the freezing was initiated. ${ }^{57} \mathrm{Fe}$ Mössbauer spectra were collected from the frozen solutions at $\mathrm{T}=22 \mathrm{~K}$ or $80 \mathrm{~K}$ in transmission mode using constant acceleration spectrometers with sources of ${ }^{57} \mathrm{Co}$ in $\mathrm{Rh}$. The spectrometers were calibrated using a $12.5 \mu \mathrm{m}$ foil of $\alpha$-Fe. The temperatures were controlled using a closed-cycle helium refrigerator from APD Cryogenics. The procedure for fitting these spectra is described in a previous study (Zhu et al., 2013). Isomer shifts are given relative to that of $\alpha$-Fe at room temperature.

Quantum chemical calculations. The above experimental analyses discovers that $\mu$-oxo dimer is the dimer present during condensed phase formation. As dihydroxo dimer is more likely 
to be the precursor for polymerization, one of the possible conversion pathways from the $\mu$-oxo to the dihydroxo dimer has been proposed based on a density functional theory (DFT) calculation, including the structures of the transition states (TS) and the reaction products (MIN) involved in the reaction path. The method ub3lyp/6-31g(d) implemented in Gaussian03, was used for the energy optimization of the structures in the gas phase first. Then the gas-phase-optimized structures were calculated for single-point energies with the inclusion of the solvation model (IEFPCM).

\section{Results}

UV-vis spectroscopy. Figure 1 shows the spectra of the $h=0.7-2.5$ solutions in the range of $350 \mathrm{~nm}-600 \mathrm{~nm}$. The UV-vis spectra at all $h$ are time dependent (Figure 1), suggesting the Fe species are changing in concentration and/or structure. At $h=0.7$, two bands at 447 and $497 \mathrm{~nm}$, characteristic of $\mu$-oxo dimers (Zhu et al., 2013), are identified in the initial spectrum using $2^{\text {nd }}$ derivatives (EA-1). The bands gradually disappear with increasing time (Figure 1). Meanwhile, a broad electron pair transition (EPT) band at $488 \mathrm{~nm}$ characteristic of Fe oxide particles with defined structure (Smolakova et al., 2010; Zhu et al., 2012), emerges and grows (Figure 1). It takes about 4 hours for the evolution to reach a pseudo steady state. These observations indicate that with increasing time the $\mu$-oxo dimer decreases in concentration while Fe oxide particles form and increase in abundance. The initial spectrum also has a weak band at $818 \mathrm{~nm}$ which shifts to $826 \mathrm{~nm}$ with time (Figure 2). This band slightly deviates from the $813 \mathrm{~nm}$ band of $\mu$-oxo dimers (Zhu et al., 2013). Fe oxide particles usually have bands at $850 \mathrm{~nm}$ and above and the band positions move to longer wavelength as particle size increases (Zhang et al., 2011; Zhu et al., 2012). Thus, the deviation and shift can be ascribed to the interference from the emerging particles that increase in abundance and/or particle size.

The UV-vis spectra of the $h=0.8$ solution show a similar trend as those of the $h=0.7$ solution, but the evolution takes only about $40 \mathrm{mins}$ to reach its pseudo steady state. As to the $h \geq$ 1 solutions (Figure 1), the two characteristic bands of the dimers are not observed, but the $488 \mathrm{~nm}$ band is pronounced initially and grows with time, indicating that a significant amount of particles had already formed by the time the first spectrum was measured (at $\sim 2 \mathrm{~min}$ ), and that their concentration increased with time. In addition, the bands of the $h \geq 1$ solutions beyond $\sim 800 \mathrm{~nm}$ are located at higher wavelength $(826-894 \mathrm{~nm})$ compared to the corresponding bands of the $h=$ 0.7 and 0.8 solutions, and also the bands dramatically shift to longer wavelengths as $h$ increases (Figure 2). This indicates that the bands must be dominated by the characteristics of the Fe oxide 
particles rather than the dimers. As explained above, the shifts imply changes in particle abundances and/or size.

Note that all solutions could also contain $\mathrm{Fe}^{3+}$ monomers because of the partial neutralization, but the UV-vis bands of monomers, located below $400 \mathrm{~nm}$, are too strong to be measured at the Fe concentration $(0.2 \mathrm{M})$ used. The presence of monomers, however, is confirmed by the EXAFS and Mössbauer analyses in the following sections.

Synchrotron-based XRD (SXRD). This approach was previously demonstrated to be effective in in situ characterizing the mineral phases of $\mathrm{Fe}$ oxyhydroxide particles being formed in partially-neutralized $\mathrm{Fe}^{3+}$ sulfate solutions (Zhu et al., 2012). In the present study, this approach was used for the partially-neutralized $\mathrm{Fe}^{3+}$ nitrate solutions (Figure 3). The peaks of the $h=0.5$ solution belong to diffuse scattering, rather than Bragg diffraction. With increasing neutralization ratio, the peaks increasingly resemble those of the 2-line ferrihydrite reference phase. The peak at $3.16 \mathrm{~nm}^{-1}$ of the $h=0.5$ solution, which can be attributed to the scattering of some unknown solution species, becomes less significant at higher $h$ because of increasing dominance of ferrihydrite particles. At each $h, \mathrm{SXRD}$ patterns show changes towards 2-line ferrihydrite with increasing time. The changes are more pronounced at lower $h$ (excluding $h=0.5$ ), suggesting more changes in Fe speciation occurring at lower neutralization ratios with time. The following QEXAFS spectroscopic analyses were used to further identify and quantify the particle phases as a function of reaction time.

QEXAFS spectroscopy. To identify the Fe polymers formed in the partially neutralized $\mathrm{Fe}^{3+}$ nitrate solutions, previous studies used EXAFS shell-by-shell fitting (Combes et al., 1989; Masion et al., 2001; Masion et al., 1997a; Masion et al., 1997b; Pokrovski et al., 2003; Rose et al., 1997a; Rose et al., 1996; Rose et al., 1997b). Such fitting determines the average local atomic structure (e.g., Fe-Fe linkages) within $6 \AA$ of the absorbing atom and potentially can be used to infer the structure of small Fe molecular clusters, such as dimers (Zhu et al., 2013). However, the average local structure information does not afford unambiguous species identifications in an admixture system containing multiple Fe species, such as the Fe solutions in this study. In addition, the presence of multiple species may make determination of the local structure using the EXAFS shell-by-shell fitting difficult. For instance, $\mathrm{Fe}^{3+}$ monomers contribute to "second shell" $\mathrm{R}$ peaks in the Fourier transforms (FT) because of the strong multiple scattering (MS) within the first O shell and the single scattering from the second-shell water molecules (Zhu et al., 2013), interfering with the FT peaks of the Fe shells corresponding to the corner-sharing structural unit $(R+\Delta R=3-3.5$ $\AA$ ) in condensed Fe species. Failure to consider the effects of MS during EXAFS shell-by-shell 
fitting can lead to errors in the determined Fe-Fe distances. Further, it is difficult to reliably determine $\mathrm{Fe}-\mathrm{Fe}$ distances when the condensed species only account for a small fraction of the total $\mathrm{Fe}$, as is typically the case in the early stages of Fe oxide formation.

Linear combination fitting (LCF). EXAFS LCF analysis, by which EXAFS spectra in $\mathrm{k}$ space of several known compounds are summed linearly to construct spectra of samples, has been used to identify and quantify each metal species in samples containing multiple species (Hansel et al., 2005; Zhu et al., 2012). The LCF analysis is not subject to the difficulties inherent in the shellby-shell analysis, and thus is more appropriate for this study. Use of EXAFS in the LCF fitting requires a pool of EXAFS spectra of known compounds or solutions, each of which ideally contains only one single Fe species. These species should encompass all possible major Fe species in the sample. An alternative approach is used in this study, which is described in detail as follows.

According to the UV-vis analysis, the $h \geq 0.7 \mathrm{Fe}$ solutions contain dimers and particles as well as monomers. The particles can be represented by the known Fe oxide phases, but it is impossible to prepare a pure solution for each type of $\mathrm{Fe}$ monomer because multiple types always coexist (except $\mathrm{Fe}\left(\mathrm{H}_{2} \mathrm{O}\right)_{6}{ }^{3+}$, a pure solution of which can be prepared under extremely acidic conditions). This is also the case for the $\mu$-oxo dimer, although solid crystals containing these dimers in a crown ether matrix can be synthesized (Junk et al., 1999). To conquer this obstacle, we fit the EXAFS spectra of the dissolved Fe species in the $h \geq 0.7$ solutions using the spectra of the $h$ $\leq 0.5$ solutions ( $h=0,0.2$ and 0.5 ) and allow their abundances to vary. As reported previously (Zhu et al., 2013), $h \leq 0.5$ solutions contain mainly $\mu$-oxo dimers, $\mathrm{Fe}\left(\mathrm{H}_{2} \mathrm{O}\right)_{6}{ }^{3+}$, and a small amount of $\mathrm{Fe}(\mathrm{OH})\left(\mathrm{H}_{2} \mathrm{O}\right)_{5}{ }^{2+}$. The molar fractions of each species in these three solutions are provided in EA2. The spectra of the $h \geq 0.7$ solutions can be fit with the spectra of the $h \leq 0.5$ solutions and Fe oxide solid phases, allowing quantification of the monomer and dimer concentrations. For example, the dimer $\left(F_{\text {dimer }}\right)$ atomic fraction can be calculated as:

$$
F_{\text {dimer }}=f_{\mathrm{LCF}, \mathrm{h} 0} \times f_{\text {dimer, } \mathrm{h} 0}+f_{\mathrm{LCF}, \mathrm{h} 02} \times f_{\text {dimer, } \mathrm{h} 02}+f_{\mathrm{LCF}, \mathrm{h} 05} \times f_{\text {dimer, } \mathrm{h} 05}
$$

where $f_{\mathrm{LCF}, \mathrm{i}}$ represents LCF-determined contribution of each solution (i corresponds to each of the $h=0,0.2$ and 0.5 spectra) to the spectrum fit, and $f_{\text {dimer, } i}$ represents the dimer fraction in this solution, which is known as shown in EA-2. The $f_{\mathrm{LCF}, i}$ values can be negative or greater than 1 as long as the ultimate $F_{\text {dimer }}$ value is between 0 and 1. EA-3 gives the LCF-determined contribution of each solution, i.e., $f_{\mathrm{LCF}, i}$ values, for the time-resolved EXAFS spectra of solution samples partially neutralized at $h=0.7,0.8,1,2$ and 2.5. Figure 4 show that the LCF fits are in excellent 
agreement with the experimental data. The obtained atomic fraction of each Fe species is illustrated in Figure 5.

Solid species. For the $h=0.7$ and 0.8 samples, we tested for improvement of the fitting by inclusion of component spectra for 2-line ferrihydrite, goethite $(\alpha-\mathrm{FeOOH})$, or lepidocrocite $(\gamma-\mathrm{FeOOH})$. Inclusion of these solids slightly improves the fitting for the early reaction stage. This indicates that the abundance of solids is very low initially, if present at all, and that the abundance of solids increases with time. The red shift of the $\sim 800 \mathrm{~nm}$ band in the first UV-vis spectrum of the $h=0.7$ and 0.8 solutions supports the presence of Fe oxides at low concentration (Figure 2). Inclusion of solids dramatically improves fitting for the late stage, with ferrihydrite inclusion clearly yielding the best fit (EA-4). This result indicates that ferrihydrite is present in late stage solutions.

For the $h \geq 1$ samples, using 2-line ferrihydrite in LCF results in much better fits than using lepidocrocite and goethite (EA-4). Interestingly, inclusion of a small fraction of lepidocrocite ( $5 \%$ ) in fitting $h=2$ and 2.5 samples significantly improves the goodness of fit (by $15 \%$ and $27 \%$, respectively, EA-4). The lepidocrocite fraction, however, is below the detection limit of LCF analysis and its existence in the solution is questionable.

As shown in Figure 5, the solid concentration (probably ferrihydrite) increases with increasing time and $h$. The curves of both $h=0.7$ and 0.8 display a sigmoidal shape, and it takes about 4 hours and 1 hour, respectively, to reach plateau, consistent with the time required for features in the UV-vis spectra to reach steady state. At $h=0.7$, the solid concentration in the early stage is very low and does not change appreciably with time, suggesting the existence of an incubation period. A similar lag also occurs in the $h=0.8$ case, but it is shorter than in the $h=0.7$ solution. In contrast, there is no evidence for an initial incubation period in curves of the $h \geq 1$ solutions, and significant amounts of ferrihydrite are present at first measurement (the fraction of Fe as ferrihydrite ranging from 0.1 to 0.6 ).

To further investigate ferrihydrite formation, the kinetic data were fit with an Avrami model, yielding parameters given in Table 1 . The $\mathrm{k}_{\mathrm{a}}$ values increase, indicating that ferrihydrite formation becomes faster as $h$ increases. The parameter $\mathrm{n}_{a}$, which relates to particle shape, has values close to 2 at $h=0.7$ and 0.8 , suggesting formation of platy ferrihydite particles, as reported in previous studies (Harrington et al., 2011b; Schwertmann et al., 1999). The smaller $\mathrm{n}_{a}$ values at $h \geq 1$ could be due to inability to collect data very early in the experiment. 
Dissolved species. The spectral fit data indicate that hydrated monomer $\left(\mathrm{Fe}\left(\mathrm{H}_{2} \mathrm{O}\right)_{6}{ }^{3+}\right)$ and $\mu$-oxo dimer are the dominant species in all experiments (Figure 5). The initial dimer concentration depends upon $h$, increasing to the maximum $56 \%$ at $h=0.8$ and then decreasing to $10 \%$ at $h=2.5$ (Figure 5 a). Subsequently, the $\mu$-oxo dimer concentration decreases with time at each $h$ (Figure 3 b-f).

Intriguingly, the $\mathrm{Fe}\left(\mathrm{H}_{2} \mathrm{O}\right)_{6}{ }^{3+}$ concentration increases significantly with time at $h=0.7,0.8$ and 1 (Figure 5, b - d), yet it barely changes with time in the $h=2$ and 2.5 solutions (Figure 3, e f). However, results for the $h=2$ and 2.5 solutions may be inaccurate, as both UV-vis and EXAFS spectral changes are small and fitting is subject to a larger relative error than in other solutions. The hydrolyzed $\mathrm{Fe}$ monomer $\left(\mathrm{Fe}\left(\mathrm{H}_{2} \mathrm{O}\right)_{5}(\mathrm{OH})^{2+}\right)$ accounts for $\sim 5 \%$ of the total $\mathrm{Fe}$ in all experiments, and its concentrations slightly decrease with time. According to the species distribution calculation, the concentrations of monomers such as $\mathrm{Fe}(\mathrm{OH})_{2}\left(\mathrm{H}_{2} \mathrm{O}\right)_{4}{ }^{+}, \mathrm{Fe}(\mathrm{OH})_{3}\left(\mathrm{H}_{2} \mathrm{O}\right)_{3}{ }^{0}$ and $\mathrm{Fe}(\mathrm{OH})_{4}\left(\mathrm{OH}_{2}\right)^{-}$are extremely low (atomic fractions $<10^{-3}, 10^{-8}$ and $10^{-15}$, respectively), thus they are not included in Figure 3.

The $\mathrm{pH}$ of the solutions, ranging from 1.85 to 2.7 , decreases with time after the base addition, except for the $h=0.7$ solution (Figure $5 \mathrm{~g}$ ). The increase in $\mathrm{pH}$ in the $h=0.7$ solution is slight, and may be a measurement error. Using the $\mathrm{pH}$ values and total dissolved Fe concentrations (the total minus the Fe concentration in solid forms) and assuming that the dissolved species reach equilibrium instantaneously, we estimated the time-dependent concentration of the dissolved $\mathrm{Fe}$ species using the reported dissociation and formation constants (Stefansson, 2007) (EA-5). The results are broadly similar to those obtained from spectral fitting, validating the assumption.

The average local structures. The LCF results are consistent with the changes observed in the EXAFS Fourier transforms, as shown in Figure 6. For the $h=0.7,0.8$ and 1 solutions, the $\mathrm{O}$ peak maxima significantly shift to lower $\mathrm{R}$ with increasing time, suggesting a shortening of the average $\mathrm{Fe}-\mathrm{O}$ bond length, which can be ascribed to the changes in the abundance of both $\mu$-oxo dimers and ferrihydrite as shown in the LCF analysis. The Fe octahedron in the $\mu$-oxo dimer has five quite long $\mathrm{Fe}-\mathrm{OH}_{2}$ bonds ( $2.08 \AA$ on average) whereas the $\mathrm{Fe}-\mathrm{O}$ bond lengths in ferrihydrite are shorter than that of $\mathrm{Fe}\left(\mathrm{H}_{2} \mathrm{O}\right)_{6}{ }^{3+}\left(d_{\mathrm{Fe}-\mathrm{OH} 2}=2.0 \AA\right.$ ) (Junk et al., 1999; Junk et al., 2002; Zhu et al., 2013). Consequently, the decreasing abundance of $\mu$-oxo dimers and the increasing abundance of ferrihydrite contribute to the Fe-O bond length shortening. The dimers may contribute more than ferrihydrite to the shortening because of the greater decreases in the dimer concentration. EXAFS shell-by-shell fitting results are given Table 2. 
Mössbauer spectroscopy. We recorded Mössbauer spectra at $22 \mathrm{~K}$ in zero applied field for the $h=1$ solution at 2, 30 and 350 minutes after base addition, as well as the $h=0$ solution (Figure 7). The obtained parameters are given in Table 3. The spectrum of the $h=0$ solution contains a magnetically split component $\left(\mathrm{S}_{\mathrm{a}}\right)$ with a magnetic hyperfine field $\mathrm{B}_{\mathrm{hf}} \approx 58 \mathrm{~T}$, isomer shift $\delta \approx 0.50 \mathrm{mms}^{-1}$ and a negligible quadrupole shift. This component is attributed to $\mathrm{Fe}^{3+}$ monomers $\mathrm{Fe}\left(\mathrm{H}_{2} \mathrm{O}\right)_{6}{ }^{3+}$ with slow paramagnetic relaxation (Knudsen, 1977; Knudsen et al., 1975; Koch et al., 2009; Mørup and Knudsen, 1986; Zhu et al., 2013). In addition, the spectrum contains a ferric doublet $\left(D_{a}\right)$ with a quadrupole splitting of $1.68 \mathrm{~mm} \cdot \mathrm{s}^{-1}$ and isomer shift of $0.59 \mathrm{~mm} \cdot \mathrm{s}^{-1}$ corresponding to a $\mu$-oxo dimer (Junk et al., 1999; Knudsen et al., 1975; Zhu et al., 2013). For the $h=1$ solution at $2 \mathrm{~min}$ and $30 \mathrm{~min}$, an additional sextet $\left(\mathrm{S}_{\mathrm{b}}\right)$ with a hyperfine field of about $55 \mathrm{~T}$, and an additional doublet $\left(\mathrm{D}_{\mathrm{b}}\right)$ with a quadrupole splitting of $0.64 \mathrm{~mm} / \mathrm{s}$ and an isomer shift of 0.51 $\mathrm{mm} / \mathrm{s}$, were observed. Besides these, the spectrum of the 350-min sample also contains another sextet $\left(S_{c}\right)$ with a hyperfine field of $\sim 44 \mathrm{~T}$ that could correspond to ferrihydrite, schwertmannite or lepidocrocite (Murad, 1988; Murad et al., 1988). In combination with the above EXAFS LCF analysis, we conclude that this Mössbauer component must arise from ferrihydrite, and the $\mathrm{S}_{\mathrm{b}}$ sextet may be ascribed to $\mathrm{Fe}(\mathrm{OH})\left(\mathrm{H}_{2} \mathrm{O}\right)_{5}{ }^{2+}$.

To identify the Fe species of $\mathrm{D}_{\mathrm{b}}$, a Mössbauer spectrum was collected at $80 \mathrm{~K}$ for the 350 min sample, showing that $D_{b}$ gains intensity in the expense of the $S_{c}$ sextet's intensity with increasing temperature (EA-6). This suggests that $D_{b}$ corresponds to the same Fe species (i.e., ferrihydrite) as $S_{c}$ rather than small oligomers that only produce spectral doublets and do not gain intensity as temperature increases. The doublet represents ferrihydrite particles above their superparamagnetic blocking temperature, and suggests that a fraction of the ferrihydrite particles are smaller in size or less crystalline than those giving rise to the $S_{c}$ sextet at $22 \mathrm{~K}$. We note that in order to account for species with magnetic relaxation time on the order of a few nanoseconds, especially from monomeric species, a broad singlet must also be included in the fits of all spectra.

The atomic fractions of the Fe species were obtained based on their peak areas, i.e., the recoil-free fraction of all types of Fe species were considered equal. As shown in EA-7, the monomer and particle abundances increase while the dimer abundance decreases with increasing reaction time, consistent with the EXAFS and UV-vis analyses. Note that the absolute fraction values are not correct because of the presence of the very broad singlet that is wider than the measured velocity range and accounts for more than half of the whole area of the fits. 
Quantum chemical calculations. The energy-minimized structures are given in the electronic annex (EA-8), which are used to construct a possible reaction pathway for the $\mu$-oxo to dihydroxol dimer conversion (Figure 8). This pathway consists of three major steps, i.e., dehydration, protonation of the $\mu$-oxo oxygen, and ring closure.

1) Step 1: dehydration (MIN1 $\rightarrow$ TS1 $\rightarrow$ MIN2): One $\mathrm{H}_{2} \mathrm{O}$ molecule is moved from the inner-sphere to the outer-sphere.

2) Step 2: protonation (MIN2 $\rightarrow$ TS2 $\rightarrow$ MIN3): The $\mu$-oxo $\mathrm{O}$ gets one $\mathrm{H}^{+}$from a $\mathrm{H}_{2} \mathrm{O}$ molecule. Then the $\mathrm{H}_{2} \mathrm{O}$ molecule becomes $\mathrm{OH}^{-}$.

3) Step 3: ring closure (MIN3 $\rightarrow$ TS3 $\rightarrow$ MIN4): The OH- binds to the other Fe and forms a new bridge Fe-OH-Fe, and consequently, the dihydroxo bridge forms.

Among the three, the protonation step has the largest energy barrier $(67 \mathrm{~kJ} / \mathrm{mol})$, which could be the rate-limiting step, probably leading to a slow dimer conversion rate.

\section{Discussion}

Summary and comparison to previous studies. The UV-vis analysis identified $\mu$-oxo dimers and $\mathrm{Fe}$ oxides of defined structure, and qualified their concentration changes. The in situ SXRD analysis identified the Fe oxide phase as 2-line ferrihydrite, which was confirmed by the EXAFS LCF analysis. The dimer and the Fe oxide, as well as monomers, were further quantified using the LCF analysis. In addition, the identities of the Fe species at $h=1$ and their abundance evolution trends are further corroborated by the Mössbauer analysis. Based on these analyses, we conclude that Fe monomers, dimers and ferrihydrite are the major Fe species in these partially neutralized solutions; the dimers decrease and the other two species increase in abundance with increasing reaction time. The results imply that the previously "so-called" cationic Fe polymers of indefinitive structure (Rose et al., 1997b) are actually a ferrihydrite-like phase. The goethite nanoparticles observed in Johnston and Lewis (1986) could be due to the relatively long time aging (48 - $143 \mathrm{~h})$ during which ferrihydrite could transform to goethite. It is not surprising that ferrihydrite is formed because the standard method for ferrihydrite synthesis involves quick addition of strong base to a $\mathrm{Fe}^{3+}$ solution until $\mathrm{pH}$ reaches $\mathrm{pH}$ 7. Schwertmann et al. (1999) found that a schwertmannite-like Fe oxyhydroxide phase is formed in nitrate solutions, and that this acts as a precursor and converts to ferrihydrite with time. However, their experiment was conducted at high temperature $\left(80^{\circ} \mathrm{C}\right)$ and thus the result is not directly relevant to the present study.

The trends of the abundances of the monomers and dimers with increasing time are opposite to the trends observed in Johnston and Lewis (1986), although the conclusion is the same 
regarding the absence of larger oligomers (e.g., trimers and tetramers). In contrast, edge-sharing dimers, trimers and tetramers were suggested in Rose et al. (1997b) based on numbers (CN) of neighboring Fe around the central Fe and the Fe-Fe distances obtained from EXAFS shell-by-shell fitting. However, this determination is problematic because the obtained CNs are actually equal to the atomic fraction $(F)$ of the $\mathrm{Fe}$ species times the ideal $\mathrm{CN}$ of this species, i.e. $F \times \mathrm{CN}_{\text {ideal }}$. Thus, the obtained $\mathrm{CNs}$ of $\mathrm{Fe}$ for ferrihydrite are smaller than the actual values if coexisting Fe monomers and dimers with smaller $\mathrm{CNs}$ of $\mathrm{Fe}$ are not considered in the fitting. Failure to include monomers and dimers in the fitting of EXAFS spectra (Rose et al., 1997b) could lead to misidentification of ferrihydrite particles as oligomers of some type.

The LCF analysis also suggested that a small fraction of lepidocrocite may be present at $h>1$. But this phase is not observed by the SXRD analysis, which could be ascribed to either its absence or its low concentration. Note that lepidocrocite can form from aeration of $\mathrm{Fe}^{2+}$ solution as well as from neutralization of $\mathrm{Fe}^{3+}$ solutions, as shown in Wang et al. (2015b). In addition, the use of air-dried ferrihydrite in the EXAFS LCF analysis may not perfectly represent the ferrihydrite particles being formed in solutions despite their SXRD patterns being almost identical (EA-9). This might artificially introduce lepidocrocite as another Fe solid phase in the LCF fitting results for $h>$ 1 systems.

The nucleation mechanism. Previous studies discussed the $\mathrm{Fe}$ oxide formation mechanism by assuming that the dimer is the dihydroxo form (Johnston and Lewis, 1986; Schneider, 1984; Schwertmann et al., 1999); then dimer aggregation or monomer addition to the dimers leads to formation of larger oligomers, and eventually to nuclei. This seems reasonable, as the edgesharing motif in the dihydroxo dimer is one of the essential structural units of Fe oxides. Recent studies have disagreed regarding the dimer structure in acidic nitrate and perchlorate solutions, and there is strong evidence from prior studies (Junk et al., 1999; Junk et al., 2002; Zhu et al., 2013) that the $\mu$-oxo form is the only form present. Intriguingly, the $\mu$-oxo dimer has a long Fe-Fe distance $(\sim 3.6 \AA)$ and is not structurally compatible with any known Fe oxides. We consider two nucleation pathways that differ depending on whether or not the $\mu$-oxo dimer is directly involved in the nucleation event.

In the first pathway, the $\mu$-oxo dimer participates in the nucleation and reconfigures so as to contain essential edge-sharing and corner-sharing structural units found in ferrihydrite (Step 3 in Figure 8). Quantum chemical calculations show that the two types of dimers do not differ substantially in their Gibbs free energies of formation (Panina et al., 2010; Zhu et al., 2013) and 
likely, the dominance of the $\mu$-oxo dimer is kinetically favored. Thus, it is possible that a $\mu$-oxo dimer first structurally converts to a dihydroxo dimer, and this is consumed in nucleus formation fast enough to preclude its detection in solution (Step 4 in Figure 8). Similarly, failure to detect oligomers (e.g., trimers or tetramers) does not completely rule out their importance. These also may be transient species that are short-lived intermediate products. As the neutralization ratio $h$ increases from 0 to 2.5 or $\mathrm{pH}$ increases, more ferrihydrite forms initially (Figure 5a), suggesting that high $\mathrm{pH}$ values favor the $\mu$-oxo dimer conversion to the dihydroxo dimer, or that the dihydroxo dimer forms fast from monomeric Fe(III) and rapidly reacts further. Note that the dihydroxo dimer can be either the aquo form or hydrolyzed forms by dissociating $\mathrm{H}^{+}$(Johnston and Lewis, 1986). In this model, conversion of the $\mu$-oxo dimer to the dihydroxo dimer would be the rate-limiting step for further condensation reactions (Figure 8).

In the second pathway, the nucleation reaction does not involve $\mu$-oxo dimers and it occurs through assembly of highly hydrolyzed monomers that could be neutral $\mathrm{Fe}(\mathrm{OH})_{3}\left(\mathrm{H}_{2} \mathrm{O}\right)^{0}(\mathrm{Grundl}$ and Delwiche, 1993; Pham et al., 2006; Rose and Waite, 2007). In other words, the $\mu$-oxo dimer is a metastable Fe species and has nothing to do with the Fe oxide formation, like the role Keggin $\mathrm{Al}_{13}$ clusters play in gibbsite formation (Bi et al., 2004). However, under the solution conditions used in this study (high $\left[\mathrm{Fe}^{3+}\right]$ and low $\mathrm{pHs}$ ), the $\mathrm{Fe}(\mathrm{OH})_{3}\left(\mathrm{H}_{2} \mathrm{O}\right)^{0}$ concentration is extremely low $\left(f_{\mathrm{Fe}(\mathrm{OH}) 3}<10^{-8}\right)$. Thus, $\mathrm{Fe}$ oxide formation via this pathway would occur very slowly, in contradiction to the relatively fast reactions observed in our study. If the particles nucleate and grow by addition of $\mathrm{Fe}(\mathrm{OH})_{3}\left(\mathrm{H}_{2} \mathrm{O}\right)^{0}$, the particle formation rates are proportional to the concentration of $\mathrm{Fe}(\mathrm{OH})_{3}\left(\mathrm{H}_{2} \mathrm{O}\right)^{0}$ (Pham et al., 2006; Rose and Waite, 2007). This dependence is not observed in our study (data not shown). Thus, we favor the first formation pathway, at least under the experimental conditions of this study, i.e., low $\mathrm{pH}$ and high $\left[\mathrm{Fe}^{3+}\right]$.

The second pathway may be relevant under other conditions. The dimer abundance depends on dissolved $\left[\mathrm{Fe}^{3+}\right]$ and $\mathrm{pH}$. At low $\left[\mathrm{Fe}^{3+}\right]$ and high $\mathrm{pHs}$ the $\mu$-oxo dimer fraction is low and the fractions of highly hydrolyzed monomers are high (Stefansson, 2007). Thus, these monomers could be important in the initial Fe oxide nucleation under neutral and alkaline conditions, such as Fe oxide precipitation resulted from aeration of $\mathrm{Fe}^{2+}$. (Pham et al., 2006; Rose and Waite, 2007; van Genuchten et al., 2012; van Genuchten et al., 2014a; van Genuchten et al., 2014b; Voegelin et al., 2010; Voegelin et al., 2013).

In either model, formation of ferrihydrite nanoparticles releases $\mathrm{H}^{+}$, which would favor dissociation of the $\mu$-oxo dimers into monomers (Step 5 in Figure 8) (Lente and I. Fabian, 1998). 
Such a process could explain the $\mathrm{Fe}\left(\mathrm{H}_{2} \mathrm{O}\right)_{6}{ }^{3+}$ concentration increase during ferrihydrite formation. The amount of the monomers consumed in particle formation, if any, is presumably less than the amount of monomers newly produced by dimer decomposition.

A few recent studies indicate that ferrihydrite contains structural tetrahedral $\mathrm{Fe}^{3+}(\mathrm{Gilbert}$ et al., 2013; Harrington et al., 2011a; Hiemstra, 2013; Maillot et al.; Michel et al., 2010; Michel et al., 2007; Peak and Regier, 2012). Thus, the further condensation processes, from dihydroxo dimers into large oligomers and ferrihydrite nuclei, must involve formation of tetrahedral $\mathrm{Fe}^{3+}$. As the existence of dissolved tetrahedral $\mathrm{Fe}^{3+}$ is unlikely under strong acidic conditions, tetrahedral $\mathrm{Fe}^{3+}$ formation could occur much later in the condensation reaction. In this concept the oligomers would increase to a size where well-defined (interstitial) tetrahedral sites would emerge as a consequence of the three-dimensional connection of the $\mathrm{FeO}_{6}$ octahedra. Some of these sites would become occupied during further evolution into the lowest energy structural configuration. A potential condensation pathway for formation of early oligomers is described in Figure 10. A schematic representation of Gibbs free energy of each possible species versus an arbitrary reaction coordinate for the condensation processes is provided in Figure 11.

Comparison to $\mathbf{C r}^{3+}$ and $\mathbf{A l}^{3+}$ : Similar to $\mathrm{Fe}^{3+}$, trivalent chromium $\left(\mathrm{Cr}^{3+}\right)$ and aluminum $\left(\mathrm{Al}^{3+}\right)$ are highly hydrolysable cations. But compared to $\mathrm{Fe}^{3+}$, relative lower electronegativity of $\mathrm{Cr}^{3+}$ and $\mathrm{Al}^{3+}$ results in slower hydrolysis and polymerization kinetics, and different intermediate products (oligomers and polymers) as well (Jolivet et al., 2011; Jolivet et al., 2006). These intermediate polycation products are relatively inert and have sufficiently long lifetime, enabling separation and detailed structural characterization. In partially neutralized solutions, $\mathrm{Cr}^{3+}$ dimers, trimers and tetramers have been identified (Friese et al., 2002; Stuenzi et al., 1989; Torapava et al., 2009) whereas $\mathrm{Al}_{13}$ and $\mathrm{Al}_{30}$ Keggin polycations are observed for $\mathrm{Al}^{3+}$ (Allouche et al., 2000; Johansson et al., 1960). There have been no reports for analogous $\mathrm{Cr}^{3+}$ Keggin structures, possibly connected with the strong crystal field stabilization energy of $\mathrm{Cr}^{3+}$ in octahedral coordination. Recently, Sadeghi et al. (2015) successfully synthesized $\alpha$-Keggin isomer of $\mathrm{Fe}_{13}$ oxo-iron cluster. The cluster is a polyanion stabilized by $\mathrm{Bi}^{3+}$ cation, instead of a polycation as $\mathrm{Al}_{13}$. The $\mathrm{Fe}_{13}$ polyanion rapidly aggregates to ferrihydrite nanoparticles in aqueous solution without $\mathrm{Bi}^{3+}$ stabilization. The high reactivity could be one of the reasons for that we cannot identify this cluster in the hydrolyzed nitrate solutions in the present study. The cluster may also be a transient species or is not part of the reaction sequence. Additional work is required to confirm the existence of the $\mathrm{Fe}_{13} \alpha$-Keggin cluster as an intermediate $\mathrm{Fe}$ species during ferrihydrite precipitation through $\mathrm{Fe}^{3+}$ hydrolysis and polymerization processes. 
Comparison to sulfate systems: Compared to $\mathrm{Fe}^{3+}$ hydrolysis and precipitation in nitrate solution, distinct dissolved Fe clusters and solid Fe precipitates species were found in sulfate solution under similar experimental conditions (Zhu et al., 2012). This indicates that sulfate complexes with $\mathrm{Fe}^{3+}$ in those dissolved $\mathrm{Fe}^{3+}$ species in sulfate solution, leading to a different $\mathrm{Fe}^{3+}$ hydrolysis and precipitation pathway. It is very likely that these $\mathrm{Fe}^{3+}$-sulfate clusters exist in natural acidic sulfuric waters as well, highlighting the strong control of sulfate on $\mathrm{Fe}^{3+}$ geochemistry in these environments. The structures of the $\mathrm{Fe}^{3+}$-sulfate clusters are yet unknown and warrant further studies.

\section{Conclusions}

Using multiple fast data-acquisition spectroscopic and X-ray scattering approaches, with appropriately chosen $\mathrm{Fe}^{3+}$ concentration, type of neutralization base and EXAFS fitting procedures, we discovered that the previously described "polymeric" intermediate product in partiallyneutralized $\mathrm{Fe}^{3+}$ solutions is actually ferrihydrite, representing the end solid product of the hydrolysis reaction. We further found that only $\mu$-oxo dimers, and no other polymers, are present in any substantial numbers in the neutralization systems. This fact points to a ferrihydrite formation pathway starting from $\mu$-oxo dimers which must undergo structural reconfiguration into transient dihydroxo dimers. Further condensation reactions, into oligomers and eventually the ferrihydrite phase, must occur very quickly with low activation energy barriers, such that these species, including dihydroxo dimers are not present in detectable concentrations using available methodology. By providing novel kinetic data and $\mathrm{Fe}^{3+}$ speciation analysis, this work is an important step towards a complete revelation of the complicated $\mathrm{Fe}^{3+}$ hydrolysis and polymerization chemistry. These findings are also significant considering the important role of $\mathrm{Fe}$ in many environmental and biogeochemical processes. For example, they provide a solid starting point for understanding early Fe oxyhydroxide / oxide formation under more complicated environmental conditions such as in acid mine drainage and acidic soils.

\section{Acknowledgement}

The work was supported by the US Department of Energy, Office of Basic Energy Sciences, under Award Number DE-AC02-05CH11231 to Lawrence Berkeley National laboratory. M.Z. also thanks the support from the U. S. National Science Foundation under Grant EAR-1529937. C.F. acknowledges funding from the Danish council for independent research. Use of the National Synchrotron Light Source, Brookhaven National Laboratory was supported by the U.S. DOE Office of Science, Office of Basic Energy Sciences, under Contract No. DE-AC02-98CH10886. This 
research used resources of the Advanced Photon Source, a U.S. Department of Energy (DOE) Office of Science User Facility operated for the DOE Office of Science by Argonne National Laboratory under Contract No. DE-AC02-06CH11357. Use of the Stanford Synchrotron Radiation Lightsource, SLAC National Accelerator Laboratory, is supported by the U.S. Department of Energy, Office of Science, Office of Basic Energy Sciences under Contract No. DE-AC02$76 \mathrm{SF} 00515$.

\section{Electronic Annex}

EA includes the UV-vis spectra and their second derivatives, $\mathrm{Fe}^{3+}$ speciation in $\mathrm{h} 0$, h02 and h05 solutions, molar fractions of h0, h02, h05, ferrihydrite and lepidocrocite obtained from the linear combination fitting (LCF) analysis, the goodnesses of the linear combination fits, the quantitative results of the Mössbauer analysis, DFT-predicted molecular structures, and synchrotron-based XRD patterns of wet and air dried ferrihydrite.

\section{References}

Allouche, L., Gérardin, C., Loiseau, T., Férey, G. and Taulelle, F. (2000) Al30: A Giant Aluminum Polycation. Angewandte Chemie International Edition 39, 511-514.

Bi, S., Wang, C., Cao, Q. and Zhang, C. (2004) Studies on the mechanism of hydrolysis and polymerization of aluminum salts in aqueous solution: correlations between the "Core-links" model and "Cage-like" Keggin-Al 13 model. Coord. Chem. Rev. 248, 441-455.

Bligh, M.W. and Waite, T.D. (2010) Formation, aggregation and reactivity of amorphous ferric oxyhydroxides on dissociation of $\mathrm{Fe}(\mathrm{III})$-organic complexes in dilute aqueous suspensions. Geochim Cosmochim Acta 74, 5746-5762.

Bottero, J.Y., Manceau, A., Villieras, F. and Tchoubar, D. (1994) Structure and mechanisms of formation of iron oxide hydroxide (chloride) polymers. Langmuir 10, 316-319.

Bottero, J.Y., Tchoubar, D., Arnaud, M. and Quienne, P. (1991) Partial hydrolysis of ferric nitrate salt. Structural investigation by dynamic light scattering and small-angle $\mathrm{X}$-ray scattering.

Langmuir 7, 1365-1369.

Brady, G.W., Kurkjian, C.R., Lyden, E.F.X., Robin, M.B., Saltman, P., Spiro, T. and Terzis, A. (1968) The structure of an iron core analog of ferritin. Biochemistry 7, 2185-2192.

Casey, W., Rustad, J. and Spiccia, L. (2009) Minerals as molecules-Use of aqueous oxide and hydroxide clusters to understand geochemical reactions. Chem - Eur J 15, 4496-4515.

Combes, J.M., Manceau, A., Calas, G. and Bottero, J.Y. (1989) Formation of ferric oxides from aqueous solutions: A polyhedral approach by X-ray absorption spectroscdpy: I. Hydrolysis and formation of ferric gels. Geochim. Cosmochim. Acta 53, 583-594.

Deng, Y. (1997) Formation of iron(III) hydroxides from homogeneous solutions. Water Research 31, 1347-1354.

Flynn, C.M. (1984) Hydrolysis of inorganic iron(III) salts. Chem. Rev. 84, 31-41.

Friese, J.I., Ritherdon, B., Clark, S.B., Zhang, Z., Rao, L. and Rai, D. (2002) Chromatographic Separation and Characterization of Hydrolyzed Cr(III) Species. Analytical Chemistry 74, $2977-$ 2984.

Gilbert, B., Erbs, J.J., Penn, R.L., Petkov, V., Spagnoli, D. and Waychunas, G.A. (2013) A disordered nanoparticle model for 6-line ferrihydrite. Am Mineral 98, 1465-1476. 
Grundl, T. and Delwiche, J. (1993) Kinetics of ferric oxyhydroxide precipitation. J Contam Hydrol 14, 71-87.

Hammersley, A.P. (1998) ESRF Internal Report, ESRF98HA01T, FIT2D V9.129 Reference Manual V3.1

Hansel, C.M., Benner, S.G. and Fendorf, S. (2005) Competing Fe(II)-induced mineralization pathways of ferrihydrite. Environ. Sci. Technol. 39, 7147-7153.

Harrington, R., Hausner, D.B., Xu, W., Bhandari, N., Michel, F.M., Brown, G.E., Strongin, D.R. and Parise, J.B. (2011a) Neutron pair distribution function study of two-line ferrihydrite. Environ. Sci. Technol, 45, 9883-9890.

Harrington, R., Neder, R.B. and Parise, J.B. (2011b) The nature of x-ray scattering from geonanoparticles: Practical considerations of the use of the Debye equation and the pair distribution function for structure analysis. Chemical Geology 329, 3-9.

Hiemstra, T. (2013) Surface and mineral structure of ferrihydrite. Geochimica et Cosmochimica Acta 105, 316-325.

Hu, Y., Lee, B., Bell, C. and Jun, Y.-S. (2012) Environmentally abundant anions influence the nucleation, growth, Ostwald ripening, and aggregation of hydrous Fe(III) oxides. Langmuir 28, 7737-7746.

Johansson, G., Lundgren, G., Sillén, L.G. and Söderquist, R. (1960) On the crystal structure of a basic aluminium sulfate and the corresponding selenate. Acta Chem. Scand., 14, 771.

Johnston, J.H. and Lewis, D.G. (1986) A study of the initially-formed hydrolysis species and intermediate polymers and their role in determining the product iron oxides formed in the weathering of iron, in: Long, G.J., Stevens, J.G. (Eds.), Industrial Applications of the Mössbauer effect. Plenum Press, New Yok, pp. 565-683.

Jolivet, J.-P., Chaneac, C., Chiche, D., Cassaignon, S., Durupthy, O. and Hernandez, J. (2011) Basic concepts of the crystallization from aqueous solutions: The example of aluminum oxy(hydroxi)des and aluminosilicates. Comptes Rendus Geoscience, 113-122.

Jolivet, J.-P., Chaneac, C. and Tronc, E. (2004) Iron oxide chemistry. From molecular clusters to extended solid networks. Chem. Commun. , 477-483.

Jolivet, J.-P., Henry, M. and Livage, J. (2000) Metal Oxide Chemistry and Synthesis: From Solution to Solid State. John Wiley \& Sons Inc, New York.

Jolivet, J.-P., Tronc, E. and Chan 茅 ac, C. (2006) Iron oxides: From molecular clusters to solid. A nice example of chemical versatility. Comptes Rendus Geoscience 338, 488-497.

Junk, P.C., McCool, B.J., Moubaraki, B., Murray, K.S. and Spiccia, L. (1999) Supramolecular complexation of polynuclear aqua Ions: A crown ether adduct of a $\mu$-oxo-bridged iron(III) aqua dimer. Angew. Chem. Int. Ed. 38, 2224-2226.

Junk, P.C., McCool, B.J., Moubaraki, B., Murray, K.S., Spiccia, L., Cashion, J.D. and Steed, J.W. (2002) Utilization of crown ethers to stabilize the dinuclear $\mu$-oxo bridged iron(III) aqua ion, $\left[\left(\mathrm{H}_{2} \mathrm{O}\right)_{5} \mathrm{Fe}(\mu-\mathrm{O}) \mathrm{Fe}\left(\mathrm{OH}_{2}\right)_{5}\right]^{4+}$. J. Chem. Soc., Dalton Trans. , 1024-1029.

Khalid, S., Caliebe, W., Siddons, P., So, I., Clay, B., Lenhard, T., Hanson, J., Wang, Q., Frenkel, A.I., Marinkovic, N., Hould, N., Ginder-Vogel, M., Landrot, G.L., Sparks, D.L. and Ganjoo, A. (2010) Quick extended x-ray absorption fine structure instrument with millisecond time scale, optimized for in situ applications. Rev. Sci. Instrum. 81.

Knudsen, J.E. (1977) Mossbauer spectroscopic studies of magnetic hyperfine interaction in ferric hexaaquao complex in frozen aqeuous solution. J. Phys. Chem. Solids 38, 883-896.

Knudsen, J.M., Larsen, E., Moreira, J.E. and Nielsen, O.F. (1975) Characterization of decaaquaoxodi-iron(III) by Mössbauer and vibrational spectroscopy. Acta Chem. Scand. Ser. A 29, 833839.

Koch, C.B., Rasmussen, H.K. and Mørup, S. (2009) Iron speciation in natural hyperacid water investigated by Mössbauer spectroscopy. Spectrochim Acta A 74, 928-930.

Lente, G. and I. Fabian (1998) New reaction path in the dissociation of the $\mathrm{Fe}_{2}(\mu-\mathrm{OH})_{2}\left(\mathrm{H}_{2} \mathrm{O}\right)_{8}{ }^{4+}$ Complex. Inorg. Chem. 38, 603-605. 
Magini, M. (1977) Structural relationships between colloidal solutions and hydroxide gels of iron(III) nitrate. J Inorg Nucl Chem 39, 409-412.

Maillot, F., Morin, G., Wang, Y., Bonnin, D., Ildefonse, P., Chaneac, C. and Calas, G. New insight into the structure of nanocrystalline ferrihydrite: EXAFS evidence for tetrahedrally coordinated iron(III). Geochimica et Cosmochimica Acta 75, 2708-2720.

Masion, A., Doelsch, E., Rose, J., Moustier, S., Bottero, J.Y. and Bertsch, P.M. (2001) Speciation and crystal Chemistry of iron(III) chloride hydrolyzed in the presence of $\mathrm{SiO}_{4}$ ligands. 3 .

Semilocal scale structure of the aggregates. Langmuir 17, 4753-4757.

Masion, A., Rose, J., Bottero, J.-Y., Tchoubar, D. and Elmerich, P. (1997a) Nucleation and growth Mechanisms of iron oxyhydroxides in the presence of $\mathrm{PO}_{4}$ Ions. 3. Speciation of Fe by small angle X-ray scattering. Langmuir 13, 3882-3885.

Masion, A., Rose, J., Bottero, J.-Y., Tchoubar, D. and Garcia, F. (1997b) Nucleation and growth mechanisms of iron oxyhydroxides in the presence of $\mathrm{PO}_{4}$ Ions. 4. Structure of the aggregates. Langmuir 13, 3886-3889.

Michel, F.M., Barron, V., Torrent, J., Morales, M.P., Serna, C.J., Boily, J.F., Liu, Q.S., Ambrosini, A., Cismasu, A.C. and Brown, G.E. (2010) Ordered ferrimagnetic form of ferrihydrite reveals links among structure, composition, and magnetism. Proc Natl Acad Sci U S A 107, 2787-2792.

Michel, F.M., Ehm, L., Antao, S.M., Lee, P.L., Chupas, P.J., Liu, G., Strongin, D.R., Schoonen, M.A.A., Phillips, B.L. and Parise, J.B. (2007) The structure of ferrihydrite, a nanocrystalline material. Science 316, 1726-1728.

Michot, L.J., Montarges-Pelletier, E., Lartiges, B.S., de la Caillerie, J.B.D. and Briois, V. (2000) Formation mechanism of the Ga-13 keggin ion: A combined EXAFS and NMR study. J. Am. Chem. Soc. 122, 6048-6056.

Mørup, S. and Knudsen, J.E. (1986) Mössbauer spectroscopy applied to solution chemistry Acta Chim. Hung. 121, 147-171.

Murad, E. (1988) The Mössbauer spectrum of “well”-crystallized ferrihydrite. J. Magn. Magn. Mater. 74, 153-157.

Murad, E., Bowen, L.H., Long, G.J. and Quin, T.G. (1988) The influence of crystallinity on magnetic ordering in natural ferrihydrites. Clay Miner. 23, 161-173.

Panina, N.S., Belyaev, A.N., Eremin, A.V. and Davidovich, P.B. (2010) DFT quantum-chemical study of the hydrolysis products of Fe(II) and Fe(III) aqua-complexes. Russ. J. Inorg. Chem. 80, 889-894.

Peak, D. and Regier, T. (2012) Direct Observation of Tetrahedrally Coordinated Fe(III) in Ferrihydrite. Environmental Science \& Technology 46, 3163-3168.

Pham, A.N., Rose, A.L., Feitz, A.J. and Waite, T.D. (2006) Kinetics of Fe(III) precipitation in aqueous solutions at $\mathrm{pH}$ 6.0-9.5 and $25^{\circ} \mathrm{C}$. Geochim Cosmochim Acta 70, 640-650.

Pokrovski, G.S., Schott, J., Farges, F. and Hazemann, J.-L. (2003) Iron (III)-silica interactions in aqueous solution: insights from X-ray absorption fine structure spectroscopy. Geochim.

Cosmochim. Acta 67, 3559-3573.

Ravel, B. and Newville, M. (2005) ATHENA, ARTEMIS, HEPHAESTUS: data analysis for Xray absorption spectroscopy using IFEFFIT. J Synchrotron Radiat. 12, 537-541.

Rose, A.L. and Waite, T.D. (2003) Kinetics of hydrolysis and precipitation of ferric iron in seawater. Environ. Sci. Technol. 37, 3897-3903.

Rose, A.L. and Waite, T.D. (2007) Reconciling kinetic and equilibrium observations of iron(III) solubility in aqueous solutions with a polymer-based model. Geochim. Cosmochim. Acta 71, 5605-5619.

Rose, J., Flank, A.-M., Masion, A., Bottero, J.-Y. and Elmerich, P. (1997a) Nucleation and growth mechanisms of $\mathrm{Fe}$ oxyhydroxide in the presence of $\mathrm{PO}_{4}$ ions. 2. P K-edge EXAFS study. Langmuir 13, 1827-1834. 
Rose, J., Manceau, A., Bottero, J.-Y., Masion, A. and Garcia, F. (1996) Nucleation and growth mechanisms of $\mathrm{Fe}$ oxyhydroxide in the presence of $\mathrm{PO}_{4}$ ions. 1. Fe K-edge EXAFS study. Langmuir 12, 6701-6707.

Rose, J., Manceau, A., Masion, A. and Bottero, J.-Y. (1997b) Structure and mechanisms of formation of $\mathrm{FeOOH}\left(\mathrm{NO}_{3}\right)$ oligomers in the early stages of hydrolysis. Langmuir 13, 3240-3246. Schneider, W. (1984) Hydrolysis of iron(III)- chaotic olation versus nucleation. Comm. Inorg. Chem. 3, 205-223.

Schwertmann, U., Friedl, J. and Stanjek, H. (1999) From Fe(III) ions to ferrihydrite and then to hematite. J. Colloid Interf. Sci. 209, 215-223.

Shimizu, M., Zhou, J., Schröder, C., Obst, M., Kappler, A. and Borch, T. (2013) Dissimilatory reduction and transformation of ferrihydrite-humic acid coprecipitates. Environ. Sci. Technol. 47, 13375-13384.

Smolakova, L., Grygar, T., Capek, L., Schneeweiss, O. and Zboril, R. (2010) Speciation of Fe in Fe-modified zeolite catalysts. J. Electroana. Chem. 647, 8-19.

Spiccia, L. (2004) Homopolynuclear and heteropolynuclear Rh(III) aqua ions - a review. Inorganica Chimica Acta 357, 2799-2817.

Stefansson, A. (2007) Iron(III) hydrolysis and solubility at $25^{\circ} \mathrm{C}$. Environ. Sci. Technol. 41, 6117-6123.

Stuenzi, H., Spiccia, L., Rotzinger, F.P. and Marty, W. (1989) Early stages of the hydrolysis of chromium(III) in aqueous solution. 4 . The stability constants of the hydrolytic dimer, trimer, and tetramer at 25.degree.C and I = 1.0 M. Inorganic Chemistry 28, 66-71.

Torapava, N., Radkevich, A., Davydov, D., Titov, A. and Persson, I. (2009) Composition and Structure of Polynuclear Chromium(III) Hydroxo Complexes. Inorganic Chemistry 48, 1038310388.

van Genuchten, C.M., Addy, S.E.A., Peña, J. and Gadgil, A.J. (2012) Removing arsenic from synthetic groundwater with iron electrocoagulation: An Fe and As K-Edge EXAFS study. Environ. Sci. Technol. 46, 986-994.

van Genuchten, C.M., Gadgil, A.J. and Peña, J. (2014a) Fe(III) nucleation in the rresence of bivalent cations and oxyanions leads to subnanoscale $7 \AA$ polymers. Environ. Sci. Technol. 48, 11828-11836.

van Genuchten, C.M., Peña, J., Amrose, S.E. and Gadgil, A.J. (2014b) Structure of Fe(III) precipitates generated by the electrolytic dissolution of $\mathrm{Fe}(0)$ in the presence of groundwater ions. Geochim. Cosmochim. Acta 127, 285-304.

Voegelin, A., Kaegi, R., Frommer, J., Vantelon, D. and Hug, S.J. (2010) Effect of phosphate, silicate, and $\mathrm{Ca}$ on $\mathrm{Fe}(\mathrm{III})$-precipitates formed in aerated $\mathrm{Fe}(\mathrm{II})$ - and $\mathrm{As}(\mathrm{III})$-containing water studied by X-ray absorption spectroscopy. Geochim. Cosmochim. Acta 74, 164-186.

Voegelin, A., Senn, A.-C., Kaegi, R., Hug, S.J. and Mangold, S. (2013) Dynamic Fe-precipitate formation induced by $\mathrm{Fe}$ (II) oxidation in aerated phosphate-containing water. Geochim.

Cosmochim Acta 117, 216-231.

Wang, X., Gu, C., Feng, X. and Zhu, M. (2015a) Sulfate local coordination environment in schwertmannite. Environ. Sci. Technol. (ASAP).

Wang, X., Zhu, M., Lan, S., Ginder-Vogel, M., Liu, F. and Feng, X. (2015b) Formation and secondary mineralization of ferrihydrite in the presence of silicate and $\mathrm{Mn}(\mathrm{II})$. Chemcial Geology (revision submitted). Chem. Geol.

Webb, S. (2005) SIXPack: a graphical user interface for XAS analysis using IFEFFIT. Phys.

Scripta T115, 1011-1014.

Zhang, H., Bayne, M., Fernando, S., Legg, B., Zhu, M., Penn, R.L. and Banfield, J.F. (2011)

Size-Dependent Bandgap of Nanogoethite. J. Phys. Chem. C 115, 17704-17710.

Zhu, M., Legg, B., Zhang, H., Gilbert, B., Ren, Y., Banfield, J.F. and Waychunas, G.A. (2012)

Early-stage formation of iron oxyhydroxides during neutralization of simulated acid mine drainage solutions. Environ. Sci. Technol. 46, 8140-8147. 
Zhu, M., Northrup, P., Shi, C., Billinge, S.J.L., Sparks, D.L. and Waychunas, G.A. (2014)

Structure of sulfate adsorption complexes on ferrihydrite. Environ. Sci. Technol. Lett. 1 97-101.

Zhu, M., Puls, B.W., Frandsen, C., Kubicki, J.D., Zhang, H. and Waychunas, G.A. (2013) In situ structural characterization of ferric iron dimers in aqueous solutions: Identification of $\mu$-oxo species. Inorg. Chem. 52, 6788-6797. 
Table 1. Summary of Avrami kinetics parameters for ferrihydrite formation: $F(t) / F_{\max }=1-\exp (-$ $\left.\mathrm{k}_{\mathrm{a}} \cdot \mathrm{t}^{\mathrm{na}}\right) . R$ suggests goodnesses of fits. The fits were performed on the linear relationship of $\mathrm{Ln}(-$ $\left.\operatorname{Ln}\left(1-\mathrm{F}(\mathrm{t}) / \mathrm{F}_{\max }\right)\right) \sim \operatorname{Ln}(\mathrm{t})$. The obtained intercepts and slops were used to calculate $\mathrm{k}_{\mathrm{a}}$ and $\mathrm{n}_{\mathrm{a}}$.

\begin{tabular}{ccccc}
\hline$h$ & $\ln \left(\mathrm{k}_{a}\left(\mathrm{~min}^{-\mathrm{na}}\right)\right)$ & $\mathrm{n}_{a}$ & $\mathrm{~F}_{\max }$ & $R$ \\
\hline 0.7 & $-8.00 \pm 0.722$ & $1.616 \pm 0.146$ & 0.110 & 0.765 \\
0.8 & $-5.871 \pm 0.397$ & $1.677 \pm 0.116$ & 0.143 & 0.892 \\
1 & $-0.995 \pm 0.170$ & $0.476 \pm 0.046$ & 0.211 & 0.931 \\
2 & $0.211 \pm 0.067$ & $0.245 \pm 0.021$ & 0.506 & 0.935 \\
2.5 & $0.409 \pm 0.094$ & $0.261 \pm 0.028$ & 0.707 & 0.934 \\
\hline
\end{tabular}


Table 2. Structural parameters obtained from EXAFS shell-by-shell fitting. Errors are listed in the parentheses. The oxygen shells were fitted with both single and two oxygen subshells (italic) in most of cases. Two oxygen subshells used same Debye-Waller factors.

\begin{tabular}{|c|c|c|c|c|c|c|}
\hline Samples & $\boldsymbol{R}$ & Shell & $\mathbf{C N}$ & $\operatorname{Dist}(\AA)$ & $\sigma^{2}$ & $\overline{\Delta E(e v)}$ \\
\hline$h=0.7$ & 0.0088 & $\mathrm{Fe}-\mathrm{O}$ & $4.4(0.5)$ & $2.041(0.007)$ & $0.006(0.001)$ & $5.2(1.2)$ \\
\hline \multirow[t]{2}{*}{$t=4 \min$} & 0.0049 & $\mathrm{Fe}-\mathrm{Ol}$ & $5.2(1.4)$ & $2.03(0.02)$ & $0.007(0.002)$ & $2.5(3.3)$ \\
\hline & & $\mathrm{Fe}-\mathrm{O} 2$ & $0.6(0.8)$ & $1.80(0.06)$ & 0.007 & \\
\hline$h=0.7$ & 0.0057 & $\mathrm{Fe}-\mathrm{O}$ & $4.9(0.4)$ & $2.026(0.006)$ & $0.007(0.001)$ & \\
\hline \multirow[t]{2}{*}{$t=250 \mathrm{~min}$} & 0.0053 & $\mathrm{Fe}-\mathrm{Ol}$ & $5.2(1.7)$ & $2.02(0.02)$ & $0.007(0.002)$ & $3.4(3.9)$ \\
\hline & & $\mathrm{Fe}-\mathrm{O} 2$ & $0.24(0.89)$ & $1.80(0.22)$ & 0.007 & \\
\hline$h=0.8$ & 0.0076 & $\mathrm{Fe}-\mathrm{O}$ & $4.3(0.4)$ & $2.043(0.007)$ & $0.006(0.001)$ & $5.4(1.1)$ \\
\hline \multirow[t]{2}{*}{$t=4 \min$} & 0.0039 & $\mathrm{Fe}-\mathrm{Ol}$ & $5.0(1.2)$ & $2.03(0.01)$ & $0.006(0.002)$ & $2.9(2.9)$ \\
\hline & & $\mathrm{Fe}-\mathrm{O} 2$ & $0.6(0.7)$ & $1.81(0.06)$ & 0.006 & \\
\hline$h=0.8$ & 0.0046 & $\mathrm{Fe}-\mathrm{O}$ & $4.7(0.4)$ & $2.030(0.006)$ & $0.006(0.001)$ & $4.8(0.9)$ \\
\hline \multirow[t]{2}{*}{$t=60 \min$} & 0.0027 & $\mathrm{Fe}-\mathrm{Ol}$ & $3.6(2.2)$ & $2.05(0.04)$ & $0.004(0.003)$ & $3.8(1.9)$ \\
\hline & & $\mathrm{Fe}-\mathrm{O} 2$ & $1.1(1.7)$ & $1.94(0.08)$ & & \\
\hline$h=1$ & 0.0056 & $\mathrm{Fe}-\mathrm{O}$ & $4.2(0.3)$ & $2.038(0.006)$ & $0.006(0.001)$ & $5.0(0.9)$ \\
\hline \multirow[t]{2}{*}{$t=4 \mathrm{~min}$} & 0.0010 & $\mathrm{Fe}-\mathrm{Ol}$ & $4.5(0.5)$ & $2.031(0.006)$ & $0.005(0.001)$ & $2.6(1.2)$ \\
\hline & & $\mathrm{Fe}-\mathrm{O} 2$ & $0.57(0.24)$ & $1.85(0.04)$ & 0.005 & \\
\hline$h=1$ & 0.030 & $\mathrm{Fe}-\mathrm{O}$ & $4.6(0.3)$ & $2.021(0.004)$ & $0.006(0.001)$ & $4.1(0.7)$ \\
\hline \multirow[t]{2}{*}{$t=60 \min$} & 0.0008 & $\mathrm{Fe}-\mathrm{Ol}$ & $4.5(0.7)$ & $2.02(0.01)$ & $0.005(0.001)$ & $2.6(1.1)$ \\
\hline & & $\mathrm{Fe}-\mathrm{O} 2$ & $0.55(0.37)$ & $1.88(0.06)$ & 0.005 & \\
\hline$h=2$ & 0.0084 & $\mathrm{Fe}-\mathrm{O}$ & $5.0(0.4)$ & $2.010(0.006)$ & $0.009(0.001)$ & $2.8(0.8)$ \\
\hline \multirow[t]{4}{*}{$t=4 \min$} & & $\mathrm{Fe}-\mathrm{Fe} 1$ & $1.0(1.1)$ & $3.08(0.03)$ & $0.010(0.008)$ & \\
\hline & & $\mathrm{Fe}-\mathrm{Fe} 2$ & $0.4(0.8)$ & $3.41(0.09)$ & 0.010 & \\
\hline & 0.0078 & $\mathrm{Fe}-\mathrm{Ol}$ & $1.85(1.11)$ & $1.94(0.04)$ & $0.006(0.004)$ & $2.5(1.3)$ \\
\hline & & $\mathrm{Fe}-\mathrm{O} 2$ & $3.08(1.05)$ & $2.04(0.04)$ & 0.006 & \\
\hline
\end{tabular}




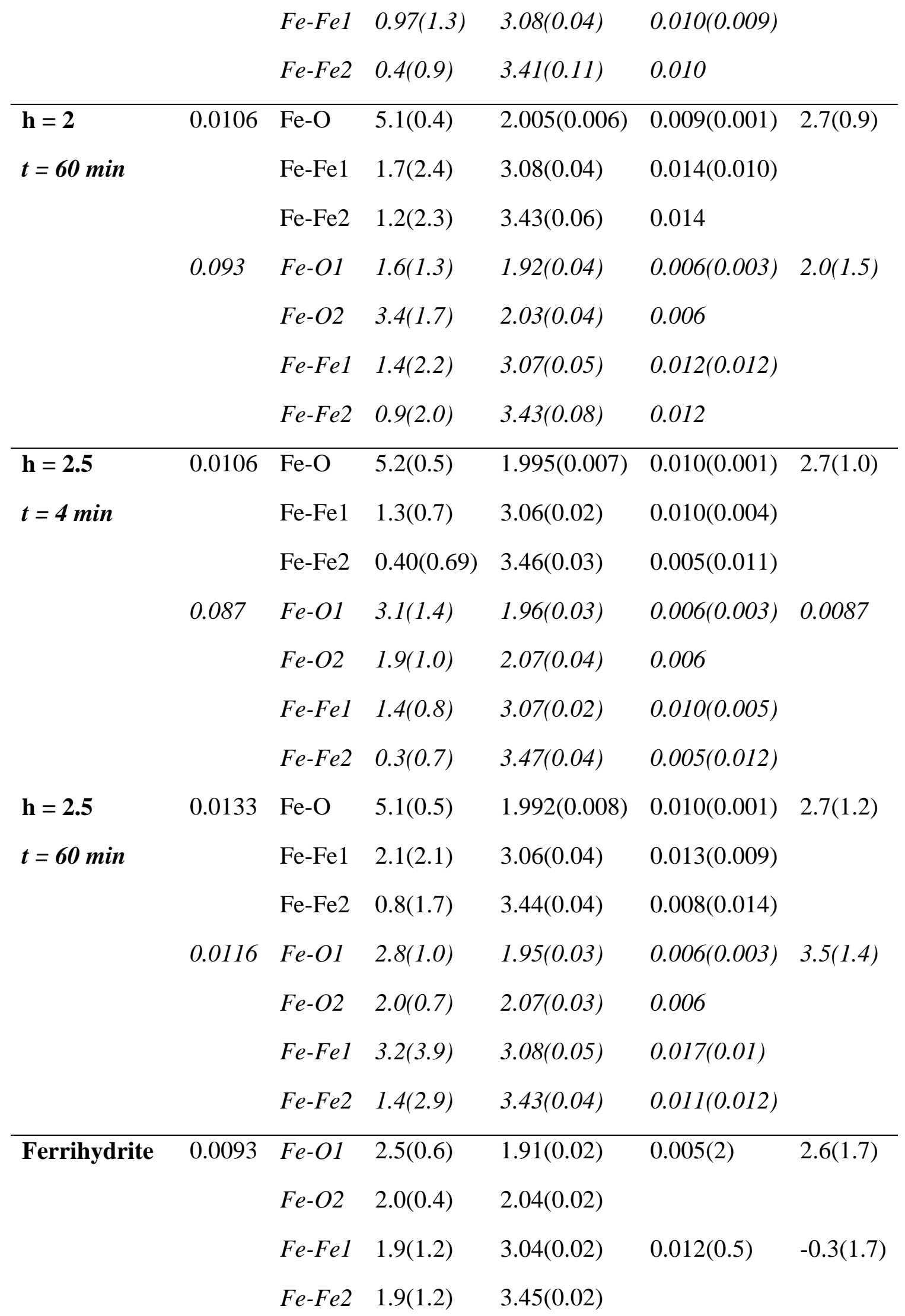




\begin{tabular}{lllllll}
\hline Lepidocrocite & 0.069 & $\mathrm{Fe}-\mathrm{O}$ & $4.8(0.4)$ & $2.004(0.005)$ & $0.007(0.001)$ & $2.6(0.7)$ \\
& & $\mathrm{Fe}-\mathrm{Fe}$ & $4.4(0.5)$ & $3.078(0.004)$ & $0.007(0.001)$ & \\
& & & & & & \\
\hline
\end{tabular}


Table 3. Fitting parameters of Mössbauer spectra of the frozen solutions. The spectra were fitted using the program mfit. Lines were constrained to be pair wise equal in width and intensity. Additionally, the relative areas of sextet lines were constrained to be 3:2:1:1:2:3.

\begin{tabular}{|c|c|c|c|c|c|}
\hline & & $\begin{array}{l}\text { Isomer shift } \\
\delta\left(\mathrm{mm} \mathrm{s}^{-1}\right)\end{array}$ & $\begin{array}{l}\text { Quadruple splitting } \\
\Delta \mathbf{E}_{\mathrm{Q}}\left(\mathrm{mm} \mathrm{s}^{-1}\right) \\
\text { /Quadrupole shift } \\
\varepsilon\left(\mathrm{mm} \mathrm{s}^{-1}\right)\end{array}$ & $\begin{array}{l}\text { Hyperfine } \\
\text { field } \\
B_{\text {hf }}(T)\end{array}$ & $\begin{array}{c}\text { Fraction } \\
(\%)\end{array}$ \\
\hline \multirow[t]{2}{*}{$h=0$} & Sextet $\left(\mathrm{S}_{\mathrm{a}}\right)$ & 0.50 & 0.00 & 57.8 & 21.4 \\
\hline & Doublet $\left(\mathrm{D}_{\mathrm{a}}\right)$ & 0.59 & 1.68 & -- & 1.5 \\
\hline $22 \mathrm{k}$ & Singlet & 0.49 & -- & -- & 77.1 \\
\hline$h=1$ & Sextet $\left(S_{a}\right)$ & 0.49 & -0.02 & 58.0 & 4.9 \\
\hline $2 \min$ & Sextet $\left(S_{b}\right)$ & 0.49 & 0.14 & 55.5 & 11.2 \\
\hline \multirow[t]{3}{*}{$22 \mathrm{k}$} & Doublet $\left(\mathrm{D}_{\mathrm{a}}\right)$ & 0.58 & 1.68 & -- & 13.7 \\
\hline & Doublet $\left(\mathrm{D}_{\mathrm{b}}\right)$ & 0.51 & 0.64 & -- & 9.8 \\
\hline & Singlet & 0.26 & -- & -- & 60.5 \\
\hline$h=1$ & Sextet $\left(\mathrm{S}_{\mathrm{a}}\right)$ & 0.47 & 0.00 & 57.8 & 6.5 \\
\hline $30 \mathrm{~min}$ & Sextet $\left(\mathrm{S}_{\mathrm{b}}\right)$ & 0.55 & 0.12 & 55.4 & 12.0 \\
\hline \multirow[t]{3}{*}{$22 \mathrm{k}$} & Doublet (Da) & 0.58 & 1.65 & -- & 13.7 \\
\hline & Doublet $\left(\mathrm{D}_{\mathrm{b}}\right)$ & 0.49 & 0.67 & -- & 10.0 \\
\hline & Singlet & 0.49 & -- & -- & 57.9 \\
\hline$h=1$ & Sextet $\left(S_{a}\right)$ & 0.49 & -0.01 & 57.9 & 10.5 \\
\hline $5 \mathrm{hr} 50 \mathrm{~min}$ & Sextet $\left(S_{b}\right)$ & 0.44 & 0.13 & 55.2 & 8.2 \\
\hline \multirow{4}{*}{$22 \mathrm{k}$} & Sextet $\left(\mathrm{S}_{\mathrm{c}}\right)$ & 0.39 & 0.00 & 43.6 & 5.9 \\
\hline & Doublet $\left(\mathrm{D}_{\mathrm{a}}\right)$ & 0.58 & 1.67 & -- & 7.5 \\
\hline & Doublet $\left(\mathrm{D}_{\mathrm{b}}\right)$ & 0.47 & 0.68 & -- & 7.6 \\
\hline & Singlet & 0.49 & -- & -- & 60.4 \\
\hline$h=1$ & Sextet $\left(S_{a}\right)$ & 0.51 & 0.05 & 57.2 & 5.8 \\
\hline $5 \mathrm{hr} 50 \mathrm{~min}$ & Sextet $\left(\mathrm{S}_{\mathrm{b}}\right)$ & 0.49 & 0.07 & 52.9 & 4.3 \\
\hline \multirow[t]{3}{*}{$80 \mathrm{k}$} & Doublet $\left(\mathrm{D}_{\mathrm{a}}\right)$ & 0.57 & 1.63 & -- & 4.5 \\
\hline & Doublet $\left(\mathrm{D}_{\mathrm{b}}\right)$ & 0.47 & 0.72 & -- & 13.9 \\
\hline & Singlet & 0.49 & -- & -- & 71.6 \\
\hline
\end{tabular}



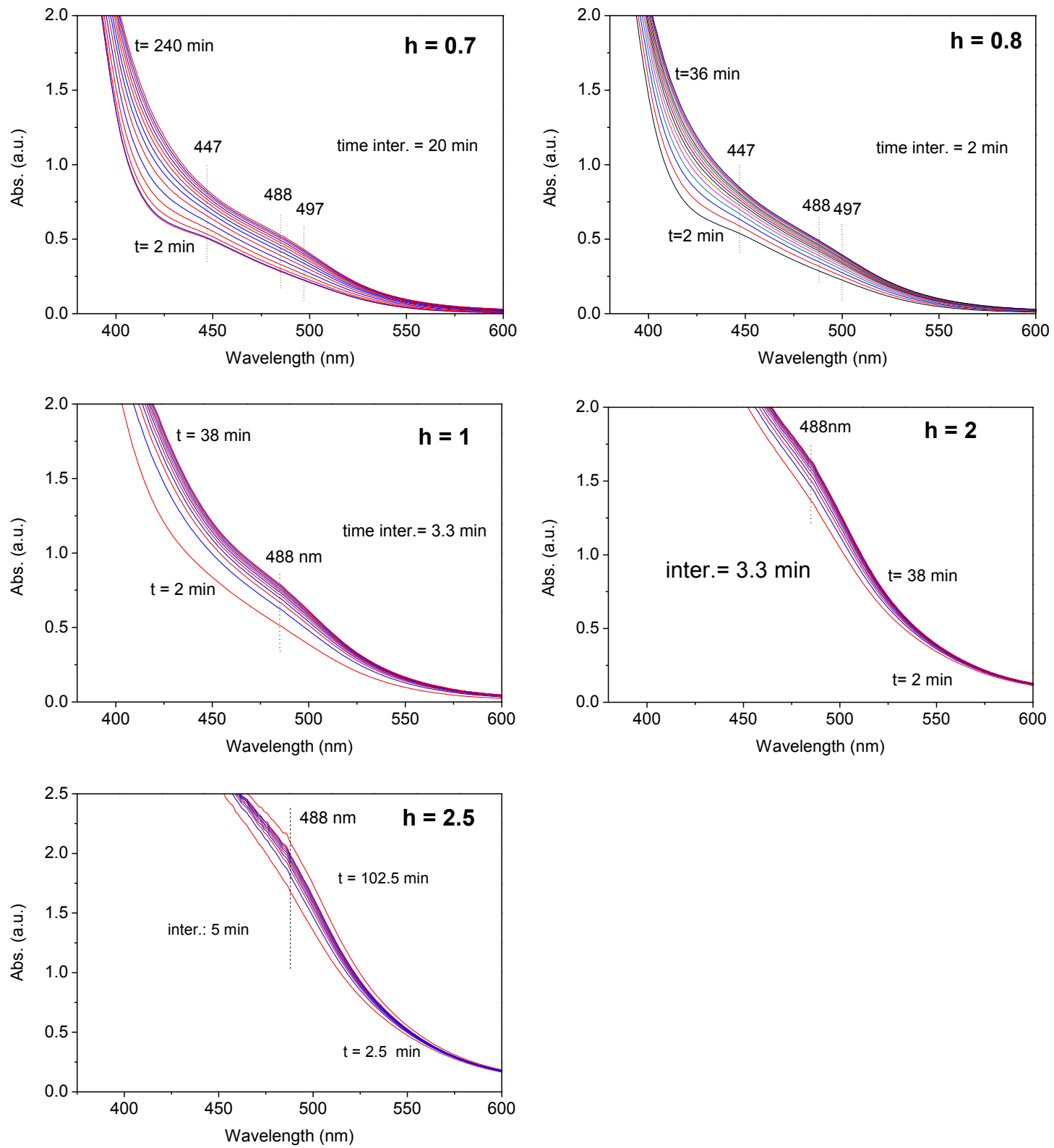

Figure 1. Time-dependent UV-vis spectra of $\mathrm{Fe}^{3+}$ nitrate solutions at neutralization ratios $(h=$ $\left.\left[\mathrm{NaHCO}_{3}\right] /\left[\mathrm{Fe}^{3+}\right]\right)$ of $0.7-2.5$ in the wavelength regime of $350-600 \mathrm{~nm}$. 

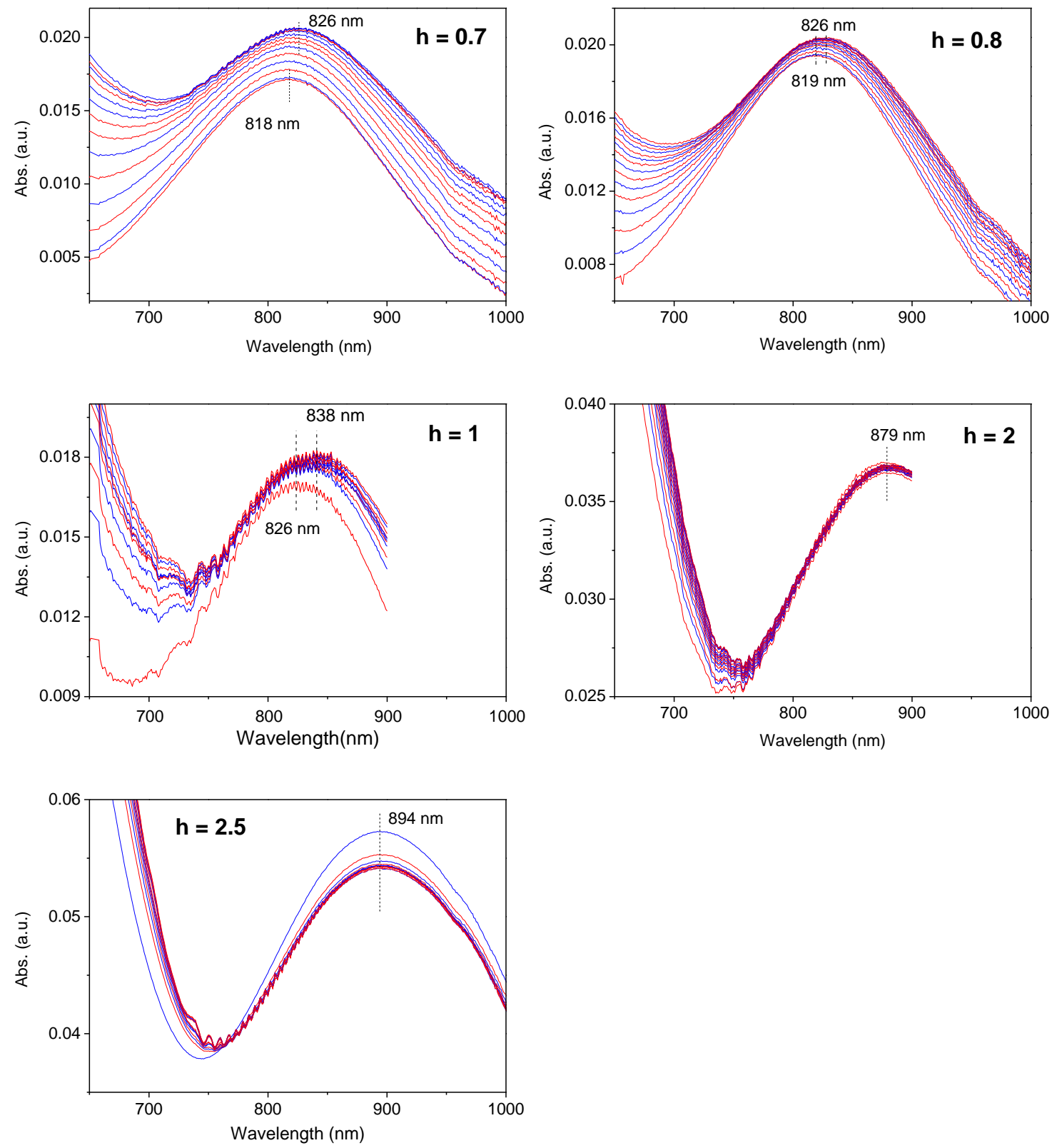

Figure 2. Time-dependent UV-vis spectra of $\mathrm{Fe}^{3+}$ nitrate solutions at neutralization ratios $(h=$ $\left.\left[\mathrm{NaHCO}_{3}\right] /\left[\mathrm{Fe}^{3+}\right]\right)$ of $0.7-2.5$ in the wavelength regime of $650-1000 \mathrm{~nm}$. 


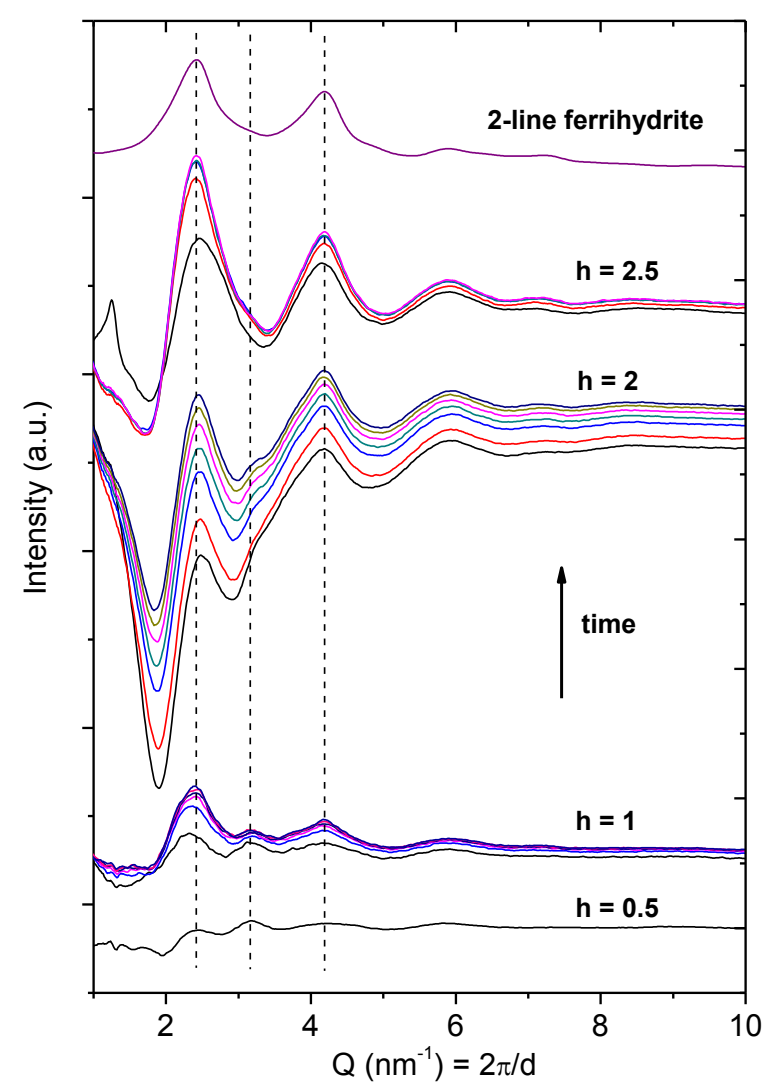

Figure 3. Time-resolved synchrotron-based X-ray diffraction patterns of each partially-neutralized $\mathrm{Fe}\left(\mathrm{NO}_{3}\right)_{3}$ solution with increasing reaction time after mixed with $\mathrm{NaHCO}_{3}$ at various $\left[\mathrm{HCO}_{3}{ }^{-}\right] /\left[\mathrm{Fe}^{3+}\right]$ ratios $(h=0.5,1,2$ and 2,5). The XRD patterns were background removed by subtracting the pattern of $h=0$ solution. At each ratio, except $\mathrm{h}=0.5$, the patterns were changing with time from the bottom to the top. The time increased from $\sim 4 \min$ to $64 \min$ for $h=1$, to $34 \min$ for $h=2$, and to $24 \min$ for $h=2.5$ with intervals all as $5 \mathrm{~min}$. 

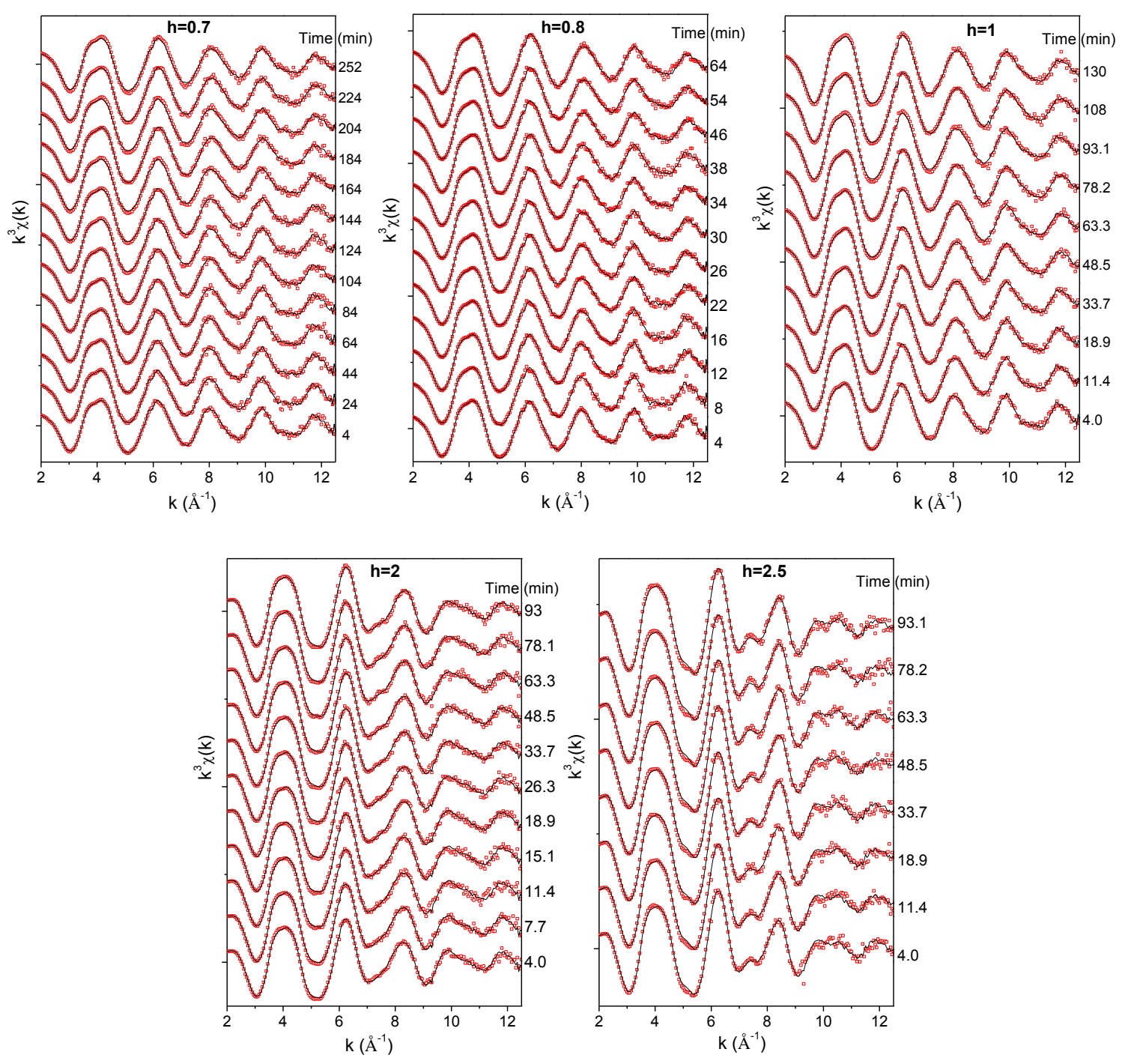

Figure 4. Linear combination fitting of the EXAFS spectra of the $h \geq 0.7$ solutions using the $h=0,0.2,0.5$ solutions and ferrihydrite. The fits for $h=2$ and 2.5 also include lepidocrocite. 

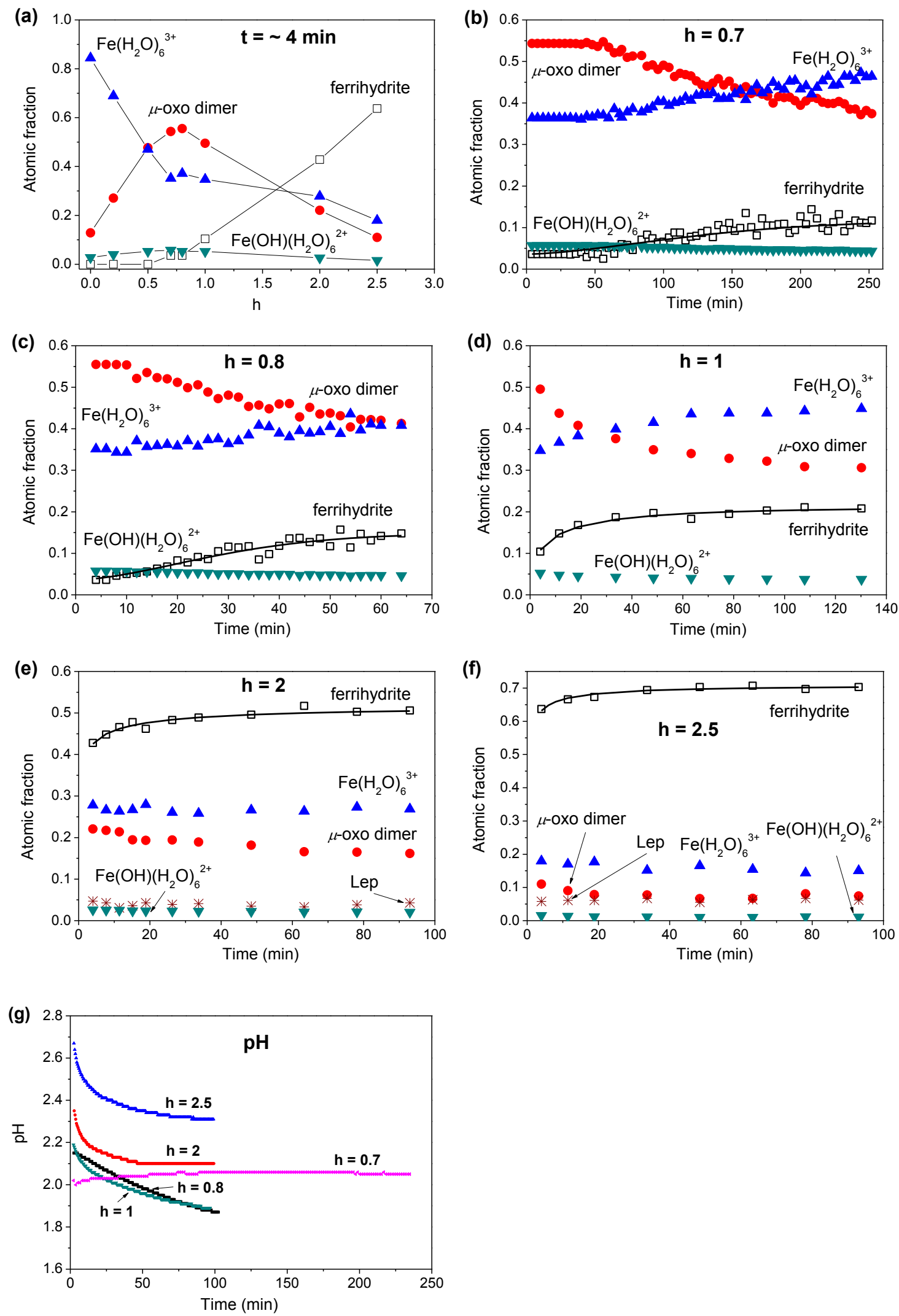
Figure 5. The initial concentration of each Fe species as a function of $h$ (a) for partially neutralized $\mathrm{Fe}^{3+}$ nitrate solutions and the species distributions over reaction time (b-f). The black curves were the fits for the ferrihydrite fractions using the Avrami kinetic model ( $c f$. Table 2). The distributions were determined using QEXAFS linear combination fitting. The relative fitting errors are about $20 \%$ for dissolved species and 5\% for solid phases. The time-dependent $\mathrm{pH}$ evolution for each solution is given in $(\mathrm{g})$.
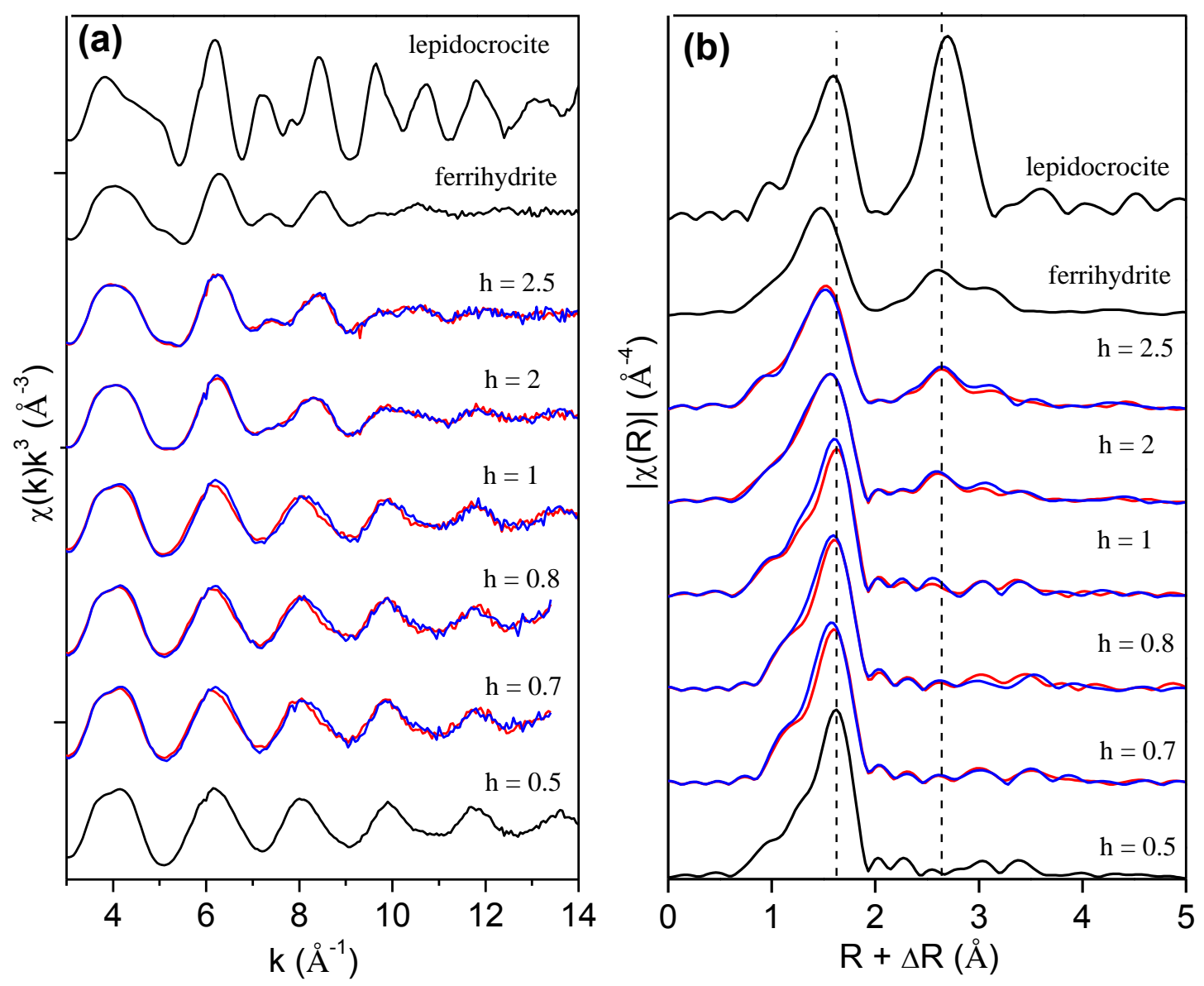

Figure 6. The representative EXAFS spectra (a) and their Fourier transforms (b) of partially neutralized $\mathrm{Fe}^{3+}$ nitrate solutions. Red curves were the spectra collected at 4 min of reaction time under each condition. Blue curves were the spectra collected at $250 \min$ for $h=0.7,65 \min$ for $h=$ $0.8,130 \min$ for $h=1,93 \min$ for $h=2$ and $h=2.5$. The spectra of the $h=0.5$ solution, ferrihydrite and lepidocrocite were plotted as references. 


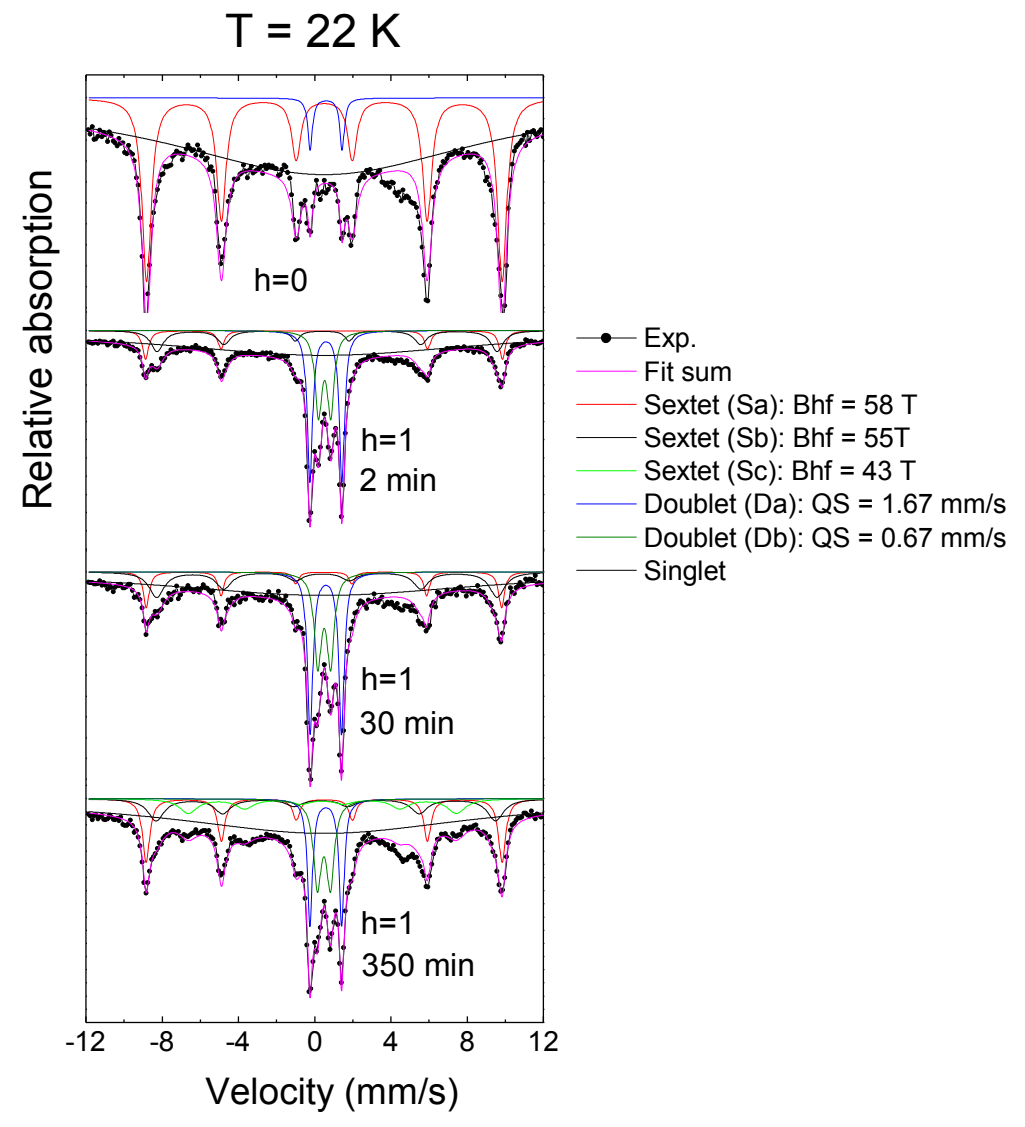

Figure 7. Mössbauer spectra and their fits of $h=0$ and 1 solutions at various reaction time. The spectra were obtained at temperature $T=22 \mathrm{~K}$. Each fit contains a singlet, multiple sextets and doublets. The spectral curve of each fit component is color coded to the identity of the component (cf. the figure legend). Fitting parameters are provided in Table 3. 


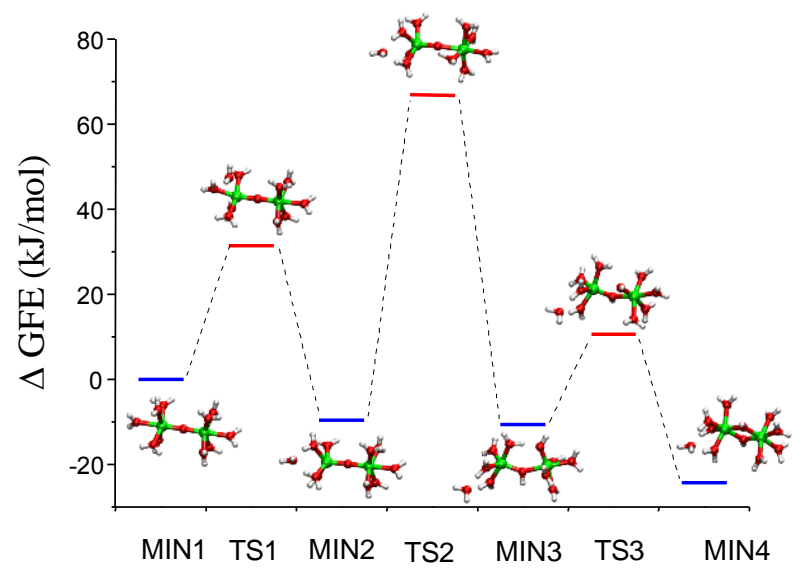

Figure 8. A proposed conversion pathway of $\mu$-oxo to dihydroxo dimer predicted based on quantum chemical calculations. MIN represents reactants, intermediate products, or products whereas TS represents transition states. Dehydration: MIN1 $\rightarrow$ TS1 $\rightarrow$ MIN2; Protonation: MIN2 $\rightarrow$ TS2 $\rightarrow$ MIN3; Ring closure: MIN3 $\rightarrow$ TS3 $\rightarrow$ MIN4. MIN stands for minima while TS for transition state. 


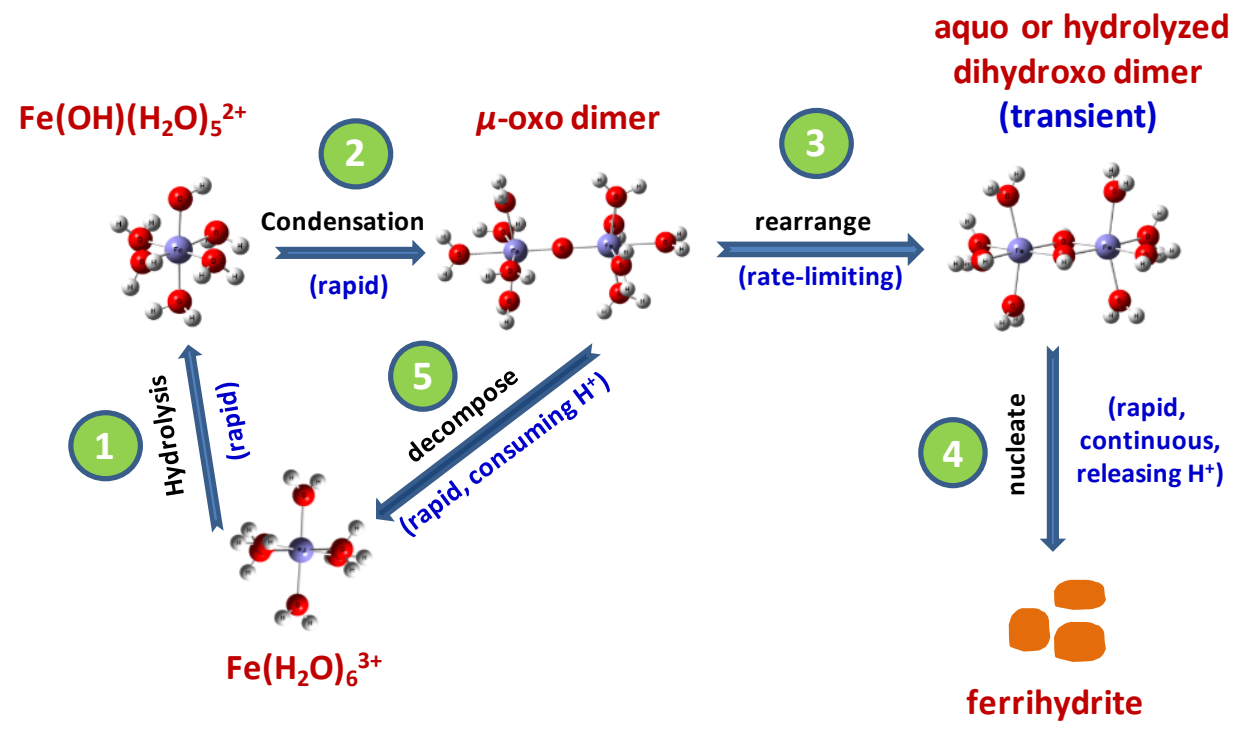

Figure 9. Reactions that are probably involved in ferrihydrite formation. 


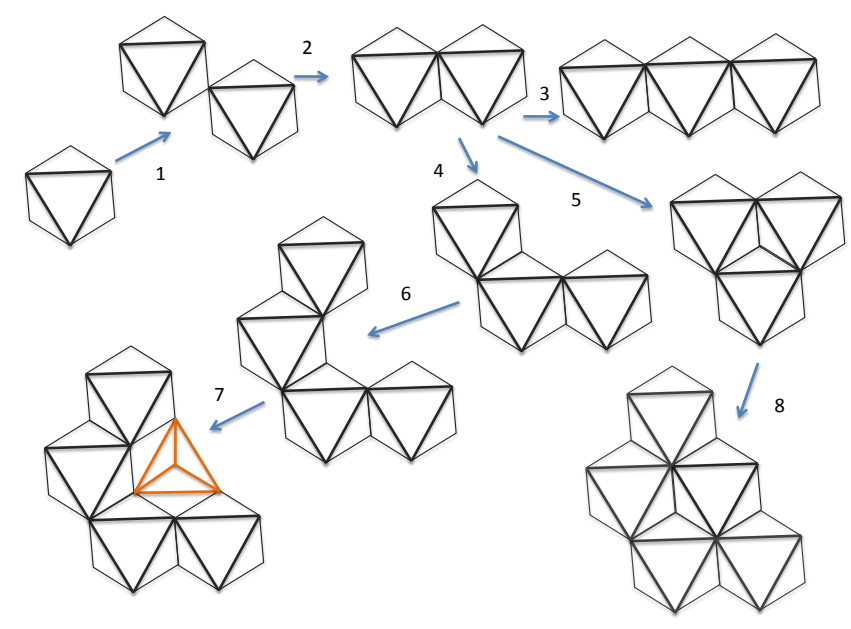

Figure 10. Potential pathways for further condensation. The pathway involving steps 4, 6 and 7 leads to formation of ferrihydrite nuclei. 


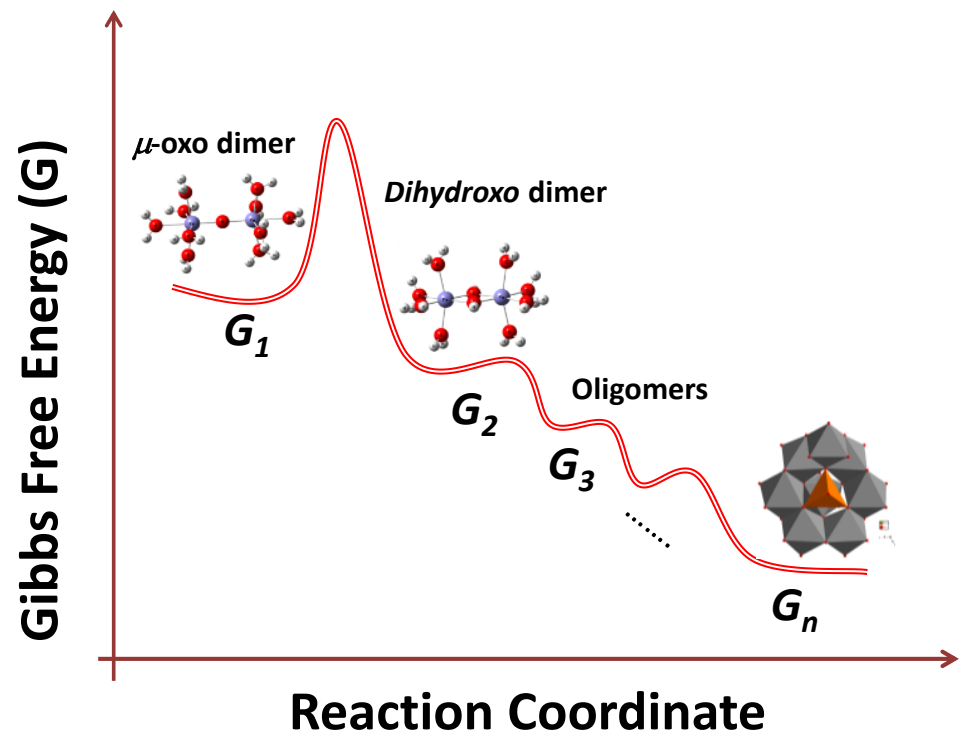

Figure 11. A schematic representation of Gibbs free energy versus an arbitrary reaction coordinate during ferrihydrite nucleation. 